\title{
Using ground-based solar and lunar infrared spectroscopy to study the diurnal trend of carbon monoxide in the Mexico City boundary layer
}

\author{
W. Stremme, I. Ortega, and M. Grutter \\ Centro de Ciencias de la Atmosfera, Universidad Nacional Autónoma de México, \\ Mexico City, Mexico \\ Received: 24 February 2009 - Published in Atmos. Chem. Phys. Discuss.: 8 May 2009 \\ Revised: 28 September 2009 - Accepted: 8 October 2009 - Published: 26 October 2009
}

\begin{abstract}
Carbon monoxide (CO) is an important pollutant in urban agglomerations. Quantifying the total burden of this pollutant in a megacity is challenging because not only its surface concentration but also its vertical dispersion present different behaviours and high variability. The diurnal trend of columnar CO in the boundary layer of Mexico City has been measured during various days with ground-based infrared absorption spectroscopy. Daytime CO total columns are retrieved from solar spectra and for the first time, nocturnal $\mathrm{CO}$ total columns using moonlight have been retrieved within a megacity. The measurements were taken at the Universidad Nacional Autónoma de México (UNAM) campus located in Mexico City $\left(19.33^{\circ} \mathrm{N}, 99.18^{\circ} \mathrm{W}, 2260 \mathrm{~m}\right.$ a.s.l.) from October 2007 until February 2008 with a Fourier-transform infrared spectrometer at $0.5 \mathrm{~cm}^{-1}$ resolution. The atmospheric $\mathrm{CO}$ background column was measured from the high altitude site Altzomoni $\left(19.12^{\circ} \mathrm{N}, 98.65^{\circ} \mathrm{W}, 4010 \mathrm{~m}\right.$ a.s.l. $)$ located $60 \mathrm{~km}$ southeast of Mexico City. The total CO column within the city presents large variations. Fresh $\mathrm{CO}$ emissions at the surface, the transport of cleaner or more polluted air masses within the field-of-view of the instrument and other processes contribute to this variability. The mean background value above the boundary mixing layer was found to be $(8.4 \pm 0.5) \times 10^{17}$ molecules $/ \mathrm{cm}^{2}$, while inside the city, the late morning mean on weekdays and Sundays was found to be $(2.73 \pm 0.41) \times 10^{18}$ molecules $/ \mathrm{cm}^{2}$ and $(2.04 \pm 0.57) \times 10^{18}$ molecules $/ \mathrm{cm}^{2}$, respectively. Continuous
\end{abstract}

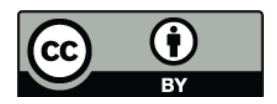

Correspondence to: W. Stremme (stremme@atmosfera.unam.mx)
$\mathrm{CO}$ column retrieval during the day and night (when available), in conjunction with surface $\mathrm{CO}$ measurements, allow for a reconstruction of the effective mixing layer height. The limitations from this simplified approach, as well as the potential of using continuous column measurements in order to derive top-down $\mathrm{CO}$ emissions from a large urban area, are discussed. Also, further monitoring will provide more insight in daily and weekly emission patterns and a usable database for the quantitative validation of $\mathrm{CO}$ from satellite observations in a megacity.

\section{Introduction}

Ambient concentrations of carbon monoxide (CO) are variable and have changed significantly since industrialization. $\mathrm{CO}$ is emitted into the atmosphere mainly from the combustion of fossil fuels, with the main contribution in urban areas coming from the transportation sector. Key reasons for investigating $\mathrm{CO}$ in the atmosphere are its danger to human health and its role in tropospheric chemistry, particularly because it affects the hydroxyl $(\mathrm{OH})$ budget (Finlayson-Pitts et al., 1992; Forster et al., 2007). For more than one decade, there has been wide interest in investigating the contribution of anthropogenic and biomass burning sources of $\mathrm{CO}$ to its observed global distributions. Insight into the amount, distribution, trends and variability of the $\mathrm{CO}$ burden on the global scale are available from surface in situ measurements, column and profile retrievals from remote ground sites and more recently from space, for example: Yurganov et al. $(2004,2005)$ studied the annual cycle and identified biomass

Published by Copernicus Publications on behalf of the European Geosciences Union. 
burning events based, among other, on CO column measurements of various NDACC (Network for the Detection of Atmospheric Composition Change) sites. Sussmann and Buchwitz (2005) and Dils et al. (2006) compared ground-based solar-FTIR column measurements with SCIAMACHY CO column results; Clerbaux et al. (2008) used recent space born $\mathrm{CO}$ measurements to study $\mathrm{CO}$ sources and visualize megacities. Senten et al. (2008) used CO column measurements at Reunion Island together with results from the inversetransport model Flexpart to identify CO sources. Additionally, they presented an overview of the established retrieval strategies and the error analysis for ground-based solar FTIR experiments with high resolution. A recent study (Halland et al., 2008) presented how the CO profiles retrieved from a satellite can be used to trace and identify convective vertical transport from the boundary layer to the free troposphere.

Accurate measurements of CO in Mexico City, the world's second most populated city, are critical in order to study its impact on human health and the environment. The emission sources of $\mathrm{CO}$ in Mexico City include traffic and industry. Since 1986, surface volume mixing ratios of CO have been measured in Mexico City by a government-run automated network for atmospheric monitoring (SIMAT, Sistema de Monitoreo Atmosférico de la Ciudad de Mexico, http://www.sma.df.gob.mx/simat). The continuous monitoring of $\mathrm{CO}$ surface mixing ratios has led to policy that has lowered the pollution levels in Mexico City during the last ten years (Molina and Molina, 2002; Stephens et al., 2008; Official Inventory, 2004). The average CO surface mixing ratios between 1990 and 2006 (Stephens et al., 2008) confirm the trend in the annual CO emission (Official Inventory, 2003, 2004, 2008), but these do not satisfactorily correlate and there are still important discrepancies in the estimation of $\mathrm{CO}$ emissions based on bottom-up approaches (Official Inventory, 2003; Schifter et al., 2005). This encourages further investigations to be carried out to determine $\mathrm{CO}$ emissions with different methodologies.

The weekly and daily patterns of the estimated $\mathrm{CO}$ emissions differ from those in the measured $\mathrm{CO}$ surface concentrations. The weekday with the highest estimated $\mathrm{CO}$ emission reported for 2006 is Saturday (Official Inventory, 2008), however, the CO surface concentration is still slightly lower on Saturdays as on normal working days (Stephens et al., 2008). The daily pattern in the CO surface concentration with a main peak at 08:00 LT (Local Time, GMT$6 \mathrm{~h}$ ) and a local minimum at 15:00 LT, does not correlate with the diurnal $\mathrm{CO}$ emission and a direct proof of the diurnal CO emission in the inventory is not possible (Official Inventory, 2008; Stephens et al., 2008). Various CO emission inventories for Mexico City have been used in studies with chemistry-transport models to compare measured and calculated concentrations (West et al., 2004; Tie et al., 2007, 2009; Zhang et al., 2009). The estimated total CO emission per year varies about $25 \%$ between the different studies and so does the temporal and spatial distributions. Zhang et al.
(2009) adapt the diurnal emission pattern for weekdays and weekends while Tie et al. (2009) keeps it constant. Both studies show that the calculated CO surface concentration correlates rather poorly with the models in the evening, during the night and on weekends. Even without horizontal CO transport, the emissions and vertical mixing of $\mathrm{CO}$ have a direct impact on the concentrations near the surface. Large uncertainties in the mixing layer height can thus lead to significant deviations of model results.

CO total columns have been derived before in Mexico City during 2003 from solar absorption measurements (de Foy et al., 2007). It was shown there that since vertical dispersion schemes in air quality models can have a large impact on simulated surface concentrations, the total column measurements of $\mathrm{CO}$ can be beneficial when used as constraint. During the MILAGRO/INTEXB campaign in March 2006, solar absorption measurements with higher spectral resolution were performed (J. Hannigan, personal communication, 2008). These measurements were taken northeast of Mexico City (T1 site in Tecamac) and during that month, the vertical structure of the boundary layer and its diurnal cycle was characterized using various instruments (Shaw et al., 2007). Solar FTIR retrievals are very sensitive to various instrumental properties and retrieval settings, so that side-by-side comparisons can be very useful in order to increase the confidence of the measurement technique. Unfortunately, the above mentioned experiments did not coincide with this study and their results can only be used as a reference. For this reason, special effort has been taken to assess the errors and precision of the results presented here (Sect. 4.5).

This paper presents the retrieved total column of urban carbon monoxide measured during daytime from solar infrared spectra and for the first time, the CO column in a megacity has been measured during the night from a ground-based instrument. Both types of measurements, when the conditions are satisfied, provide a continuous time series of the column which provides new insight into the nocturnal structure of the atmosphere. Using this information, diurnal patterns of the $\mathrm{CO}$ budget are investigated during different periods, the height and evolution of the mixing layer can be monitored under specific conditions and a new approach for estimating the effective emission of $\mathrm{CO}$ in Mexico City is proposed.

\section{Measurement realization}

The CO column measurements were taken at the Universidad Nacional Autónoma de México (UNAM) campus $\left(19.33^{\circ} \mathrm{N}\right.$, 99.18 W, $2260 \mathrm{~m}$ a.s.1.) in Mexico City between October 2007 and February 2008. The UNAM site is in the south of the city, as shown in Fig. 1, and is surrounded by several surface $\mathrm{CO}$ monitors from the local monitoring network. Additionally, background column measurements of CO were performed from 29 November to 2 December 2007 and from 15 to 18 November 2008 at the Altzomoni high 
altitude research site $\left(19.12^{\circ} \mathrm{N}, 98.65^{\circ} \mathrm{W}, 4010 \mathrm{~m}\right.$ a.s.l. $)$ located $60 \mathrm{~km}$ south-east of Mexico City, Fig. 1.

\subsection{Instrumentation}

The spectra were collected with a FTIR spectrometer (Bruker, Opag 22) with a nominal resolution of $0.5 \mathrm{~cm}^{-1}$ at a max. optical path difference (OPD) of $1.8 \mathrm{~cm}$. The FTIR is equipped with a $\mathrm{KBr}$ beamsplitter and a cryo-cooled mercury-cadmium-telluride (MCT) detector. The field of view (FOV) of the instrument is $30 \mathrm{mrad}$ but a telescope was used resulting in a FOV of $7.5 \mathrm{mrad}$. The system is coupled to a video camera and an automatic scanning mirror that actively tracks the light coming from the sun and moon. The scanning device, which has been described in more detail elsewhere (Harig, 2004; Harig et al., 2005), searches for the position of the most intense radiation in a specific wavelength range in the following manner. First, a two dimensional area is defined around the source and a low spectral resolution scan (at $20 \mathrm{~cm}^{-1}$ ) is carried out with a user-defined step size. The two stepper motors controlling the position of the scanning mirror performs a fast scan, which takes only a few seconds, and the mirror then moves to the pixel position where the highest light intensity was detected. The spectrometer then collects infrared spectra at a higher resolution of $0.5 \mathrm{~cm}^{-1}$ at this position for a fixed amount of time and then performs a new fast scan centered at the last position chosen with the maximum intensity. This system was originally designed for passive detection of pollutants and the visualization of toxic substances (Harig et al., 2007) and has been also applied for characterizing the emissions of industrial plants (Grutter et al., 2008a), airplanes (Flores-Jardines et al., 2005) and volcanoes (Grutter et al., 2008b).

\subsection{Solar measurements}

For solar absorption measurements, the scanner is optimized for tracking between 2700 and $3200 \mathrm{~cm}^{-1}$ and the system works well without frequent adjustments even when thin clouds are present. The solar angle changes at about $4.4 \mathrm{mrad} / \mathrm{min}$ so that with a FOV of $7.5 \mathrm{mrad}$, a new scan needs to be started after approximately one minute. About 60 usable spectra are recorded and averaged for further processing.

The MCT detector readily saturates when direct solar radiation is used. Therefore, the light is attenuated with a variable number of wire-mesh screens placed prior to the telescope. A disadvantage of using metal gratings at the entrance of the telescope (with 4 times magnification) is that the thermal emission of the mesh-filter interferes in the region between 800 and $2000 \mathrm{~cm}^{-1}$ and can influence the spectrum in the region where $\mathrm{CO}$ is evaluated. This thermal emission varies with the temperature of the grating and a three-step correction is applied to account for this interference; first, a background spectrum is chosen from a library of thermal

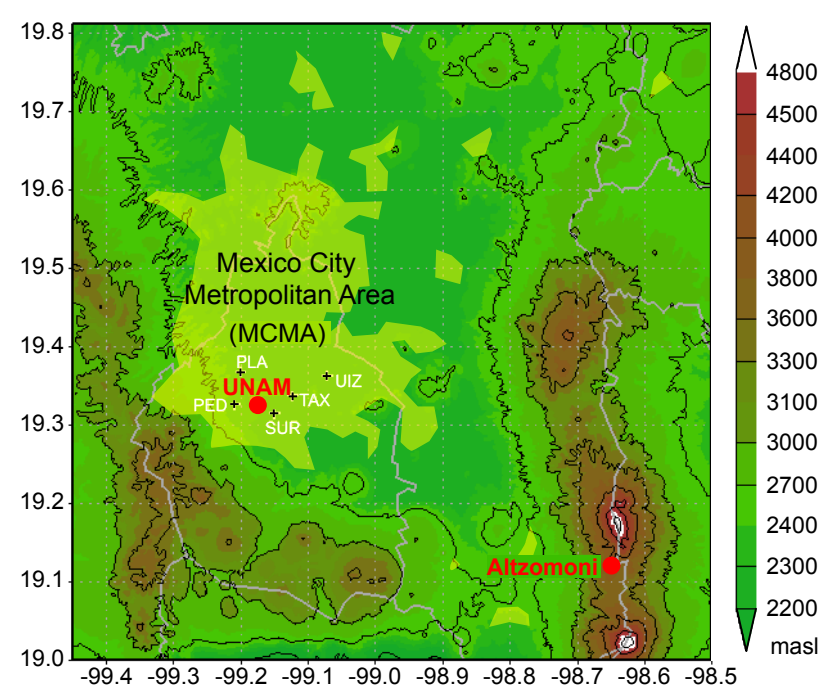

Fig. 1. Topographical map of Mexico City and its surroundings. The yellow area depicts the Mexico City metropolitan area (MCMA) and the red dots indicate the location of the FTIR sites. The black crosses indicate the used surface monitoring sites (RAMA, http://www.sma.df.gob.mx/simat/.

emission spectra at different grating temperatures created in the laboratory (the selection criteria are the correlation in the regions $620-700$ and $1500-1650 \mathrm{~cm}^{-1}$, where water vapour $\left(\mathrm{H}_{2} \mathrm{O}\right)$ and carbon dioxide $\left(\mathrm{CO}_{2}\right)$ totally absorb and remove the sunlight). In a second step, the background is scaled and corrected for offset before subtracting it from the measured radiance spectrum, Fig. 2. In the last step, the regions of total absorption in the atmosphere between 2000 and $2200 \mathrm{~cm}^{-1}$ are used to fit a straight line, which is then also subtracted from the measured spectra. This last correction removes additional effects from the thermal emission of the spectrometer and improves the spectral correction, especially in the region of evaluation, Fig. 2, inset.

The solar absorption measurements presented in this study were made between October 2007 and February 2008 from 08:30-17:30 LT. An attempt was made to record spectra on most working days with blue sky or thin cloud conditions. The intensity of the recorded spectra, as well as sky images taken automatically after each tracking position are used to classify usable data.

\subsection{Lunar measurements}

The temperature distribution of the moon's surface is strongly variable, with around $400 \mathrm{~K}$ at the warmest points on the bright side and as low as $200 \mathrm{~K}$ on the dark side (Pugacheva and Shevchenko, 2000). The radiation of the moon consists of two parts, the reflection from the sun and the thermal emission of the moon itself (Notholt et al., 1993). Both parts have a different spectral distribution; The sun has its maximum near $20000 \mathrm{~cm}^{-1}$ and the moon's thermal 


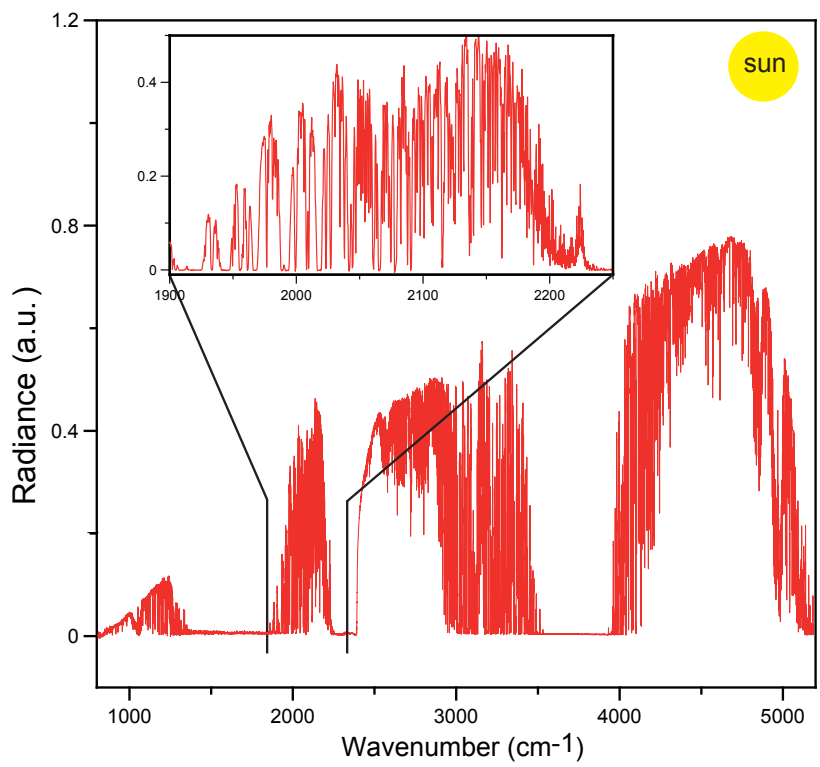

Fig. 2. Typical solar spectrum (large box) recorded at the UNAM site after a background (thermal emission) subtraction (step 2). The small box (inset) shows the same solar spectrum in the region about the $\mathrm{CO}$ band after a further $\mathrm{CO}$ specific correction (step 3).

radiation has, according to its mean temperature, a maximum around $1000 \mathrm{~cm}^{-1}$.

Below $2200 \mathrm{~cm}^{-1}$, the thermal emission dominates the spectrum as shown in Fig. 3. Even though the reflected sun intensity recorded with our telescope and MCT detector shows a relatively low signal to noise ratio (Fig. 3 around $2400 \mathrm{~cm}^{-1}$ ), the thermal radiation integrated over the observed half sphere of the moon is sufficient for the evaluation of CO during full moon and up to one week before and after. On the other hand, the measured atmospheric background radiation consists of thermal emission from the instrument, back-scattered thermal emission from the earth and self emission of the atmosphere. Depending on the lunar zenith angle and the time of the day, these will have different contributions that cannot be neglected, Fig. 3. The contribution of the background emission is relatively small during a full moon but it is still necessary to record background spectra in adequate time intervals. The background spectra were recorded approximately every hour towards a similar zenith angle of the moon.

Tracking of lunar radiation in this urban environment worked best in the spectral region between 2000 and $2200 \mathrm{~cm}^{-1}$, because here the contrast between the moon and interferences from thin clouds is higher than in the spectral region near the maximum intensity of the moon ( 800 to $1000 \mathrm{~cm}^{-1}$ ). However, better tracking was obtained a few days before and after full moon and during daylight using a wider spectral region (900 and $2200 \mathrm{~cm}^{-1}$ ). Because of the relatively low intensity available for tracking and measuring lunar absorption spectra, the tracking frequency was

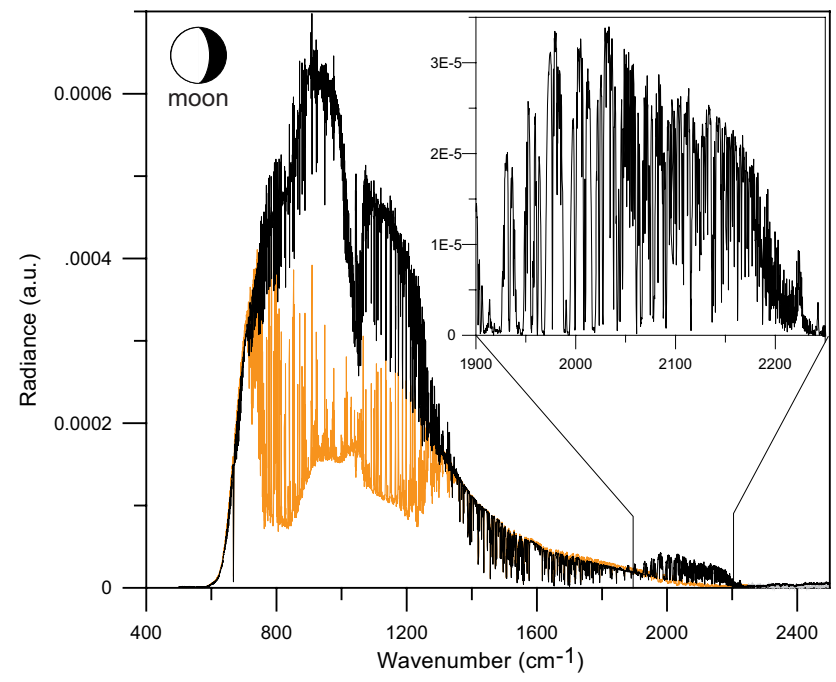

Fig. 3. Lunar spectrum in black (large box) recorded at the UNAM site around full moon directly after the Fourier-transformation (step 1) and in orange the atmospheric (+ instrumental) self emission. Moon and thermal emission spectra have to be recorded with the same zenith angle and at almost the same time, so that the atmospheric states are comparable. The corrected lunar spectrum around $\mathrm{CO}$ band is shown in the small box (step 3).

increased to every $5 \mathrm{~s}$ resulting in an increased number of usable spectra for further averaging and processing. Tracking the moon in the infrared worked even during the moon eclipse on 21 February in 2008 and in the presence of daylight, which provided the possibility for comparing the results from simultaneous solar and lunar retrievals.

The procedure for preparing the moon spectra for the $\mathrm{CO}$ analysis is done in three steps: 1) The background spectra, which is valid for the particular time frame, is subtracted. 2) A second order polynomial is fitted to the region of total absorption around the $\mathrm{CO}$ band and is subsequently subtracted. The self-emission correction of the instrument is done according to Burton et al., 2001. They used lunar spectroscopy to investigate the emission of $\mathrm{SO}_{2}$ from volcanoes during the night analyzing at $2500 \mathrm{~cm}^{-1}$. The correction for $\mathrm{CO}$ is more pronounced since the analysis is at lower energy (near $2100 \mathrm{~cm}^{-1}$ ). 3) All spectra within a $10 \mathrm{~min}$ time period are averaged to have a sufficiently high signal-to-noise ratio.

\section{CO column retrieval}

The CO columns from solar and lunar absorption spectra in Mexico City were retrieved using the SFIT2 code (Pougatchev and Rinsland, 1995). This radiative transfer and profile retrieval algorithm is mainly used for the analysis of solar ground-based spectra from high-resolution instruments. As we will demonstrate, the use of this code for moderate-resolution spectra gives acceptable results for the goals sought in this work. 
The inversion of gas profiles with SFIT2 was originally based on "Optimal Estimation Theory" (OET) described by Rodgers (1976) and uses an a priori profile and a covariance matrix (Sa). The SFIT2 code (version rdrv.3.90) is able to read in a regularization matrix $\mathbf{R}=\mathbf{S a}^{-1}$ so that the cognate constraint approaches suggested by Tikhonov (1963); Steck (2002); von Clarmann and Grabowski (2007) can be realized. The main difference in the mentioned retrieval approaches are their goals, aiming either to get the best estimation for one single atmospheric state (OET) or to reduce systematic hidden a priori information for a later (time) series analysis (von Clarmann and Grabowski, 2007). The constraint in groundbased solar retrievals or for NADIR sounders, for example, is crucial and different for each experiment (Eremenko et al., 2008; Emmons et al., 2008; Luo et al., 2007).

The atmosphere above the measurement site is described with 29 layers from $2.260 \mathrm{~km}$ up to $100 \mathrm{~km}$ using the temperature and pressure profiles from the continuous radiosonde measurements taken twice a day by the Servicio Meteorologico National in Mexico City (SMN, 2008). SFIT2 assumes horizontal homogeneous layers and returns the direct vertical column. The slant path length of the sunlight in each layer is calculated by the program RAYTRACE available with SFIT2 from the NDACC-Server. The program RAYTRACE determinates the curvature of the sunlight in the atmosphere for the given astronomical sun zenith angle, wavenumber and location and it produces the SFIT2-inputfiles which are used to change slant to vertical columns.

The spectral resolution allows retrieval of only one independent quantity that describes the volume mixing ratios (VMR) of carbon monoxide in all layers. The constraint is designed following mainly the guidance by Steck (2002); von Clarmann and Grabowski (2007). The retrieval algorithm fits the measured spectra by shifting the VMRs of the lowest three layers $(1.5 \mathrm{~km})$ using the MOPITT-a priori (NCAR MOPITT, 2008), Fig. 5a. This constraint is motivated through the assumption that there are strong $\mathrm{CO}$ variations in the mixing layer. A Gaussian distribution as is normally assumed in the OET would lead to a systematic underestimation of pollution events, also recently mentioned by Emmons et al. (2008). A freely adapted VMR value in the boundary layer region reflects the typical situation in Mexico City and when compared to a simple profile-scaling constraint, results in a lower smoothing error (Sect. 4.1) and also improves the averaging kernel in the region of interest, Fig. 5.

The spectroscopic line data are taken from the HITRAN 2004 compilation (Rothman et al., 2005) and for the sun spectra, the integrated solar model from (Hase et al., 2006) is taken. The spectral region between 2110 to $2160 \mathrm{~cm}^{-1}$ is fitted for evaluating CO. There are several reasons for using a wide spectral range in this particular case as opposed to several narrower windows as is more commonly done (Pougatchev and Rinsland, 1995; Barret et al., 2003; Yurganov et al., 2004; Sussmann and Buchwitz, 2005; Velazco et al., 2005; Fokeeva et al., 2007; Kramer, 2006; Senten
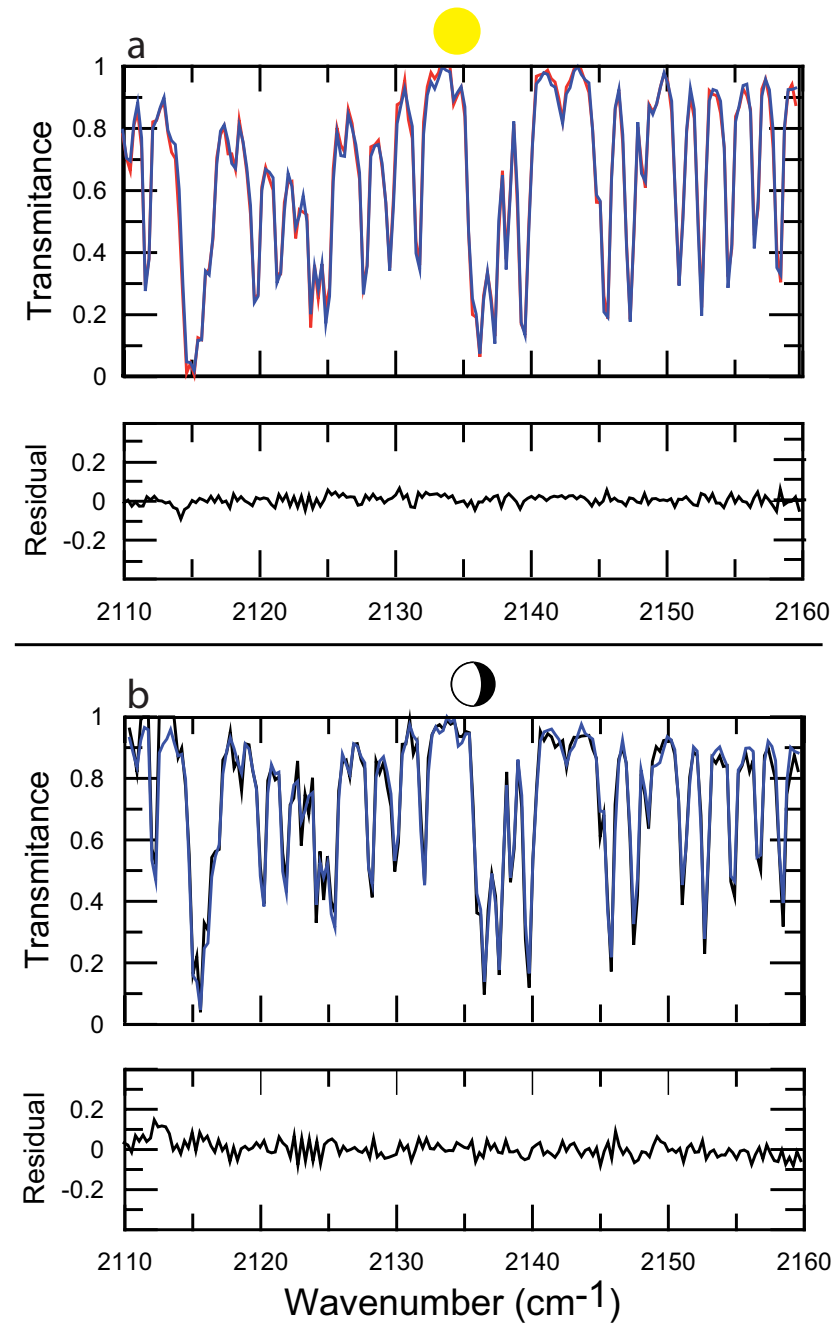

Fig. 4. Example of a column retrieval of CO from (a) a solar spectrum taken on 22 January 2008 at 10:30 LT at the UNAM site. The measured solar spectrum is in red and the simulated spectrum in blue. The retrieved $\mathrm{CO}$ column is equivalent to a $\mathrm{CO}$ column density of 3.08 molecules $/ \mathrm{cm}^{2}$. (b) Example of a lunar CO column $\left(2.74 \times 10^{18}\right.$ molecules $\left./ \mathrm{cm}^{2}\right)$ retreived on 24 February at 02:51 LT at the UNAM site. The measured lunar spectrum is in black and the simulated spectra in blue. The residuals from the fits are shown on the bottom.

et al., 2008). The reduced resolution of the spectra encourages a compromise between single line retrieval and band retrieval. The single or few line retrievals have the advantage, that the time for processing one spectrum is comparably small and a reasonably good fit can be realized. This is desirable as the forward-model error indicated solely by a systematic residual cannot be quantified. However, in this study the resolution does not allow for an easy estimation of the back-line, because the individual lines sit on a socket (the smoothed CO-band). Spectra with $0.5 \mathrm{~cm}^{-1}$ resolution do not show completely separated $\mathrm{CO}$ absorption lines and there is also a significant interference of $\mathrm{CO}_{2}, \mathrm{H}_{2} \mathrm{O}$ and $\mathrm{O}_{3}$ in this 


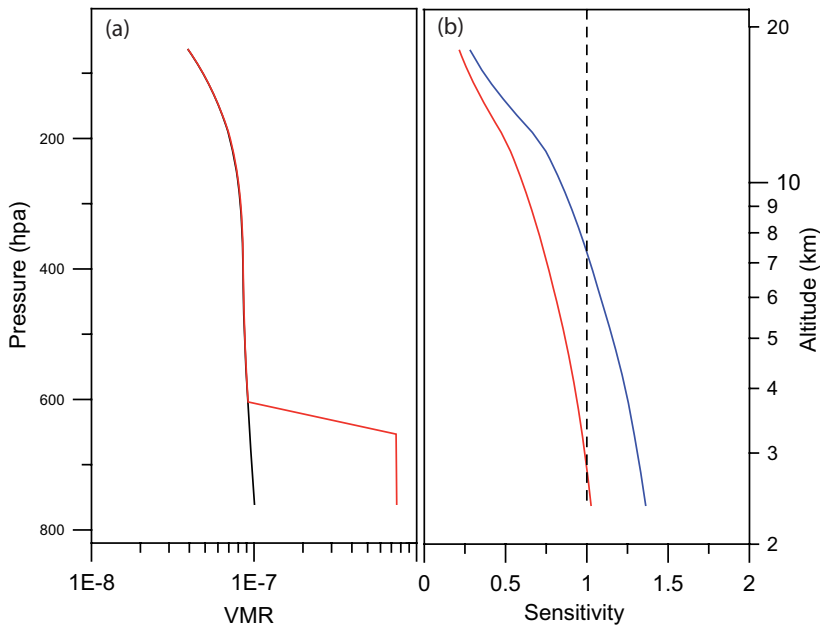

Fig. 5. Left (a): Used a priori profile (black) from MOPITT and retrieved profile (red) on 22 January 2008 at 10:29 LT at the UNAM site. Right (b): Total column averaging kernel for the used block constraint (red) and calculated around the retrieved state. The total column kernel but for a scaling constraint is shown in blue.

region. A wide spectral region contains therefore more information (Echle et al., 2000) and improves the estimation of the background slope and the columns of the interfering species. The spectral window of $50 \mathrm{~cm}^{-1}$ chosen for this study seems to contain sufficient information and is a good compromise to the computational requirements. In the used retrieval version, the instrumental line shape for the forward model was set assuming a modulation of the Boxcar-apodization according to a round aperture with an effective FOV of $41.5 \mathrm{mrad}$, which describes the divergence of the light in the interferometer.

\section{Retrieval diagnostics and error estimation}

This study presents new measurements and focuses on the relative variability and diurnal trends of the $\mathrm{CO}$ column observed above Mexico City. An analysis and a quantification of the main error sources are necessary in order to identify the potential improvements to be done in the analysis, understand its limitations and determine the use of the retrieved columns, i.e. using the $\mathrm{CO}$ columns in photochemical models or for satellite validation purposes.

Error analysis in remote sensing retrievals is still a current topic. Many different errors have to be discussed as they can play a role in the accuracy and in the precision of the retrieval (Rodgers, 1990, 2000; von Clarmann et al., 2001; Sussmann and Borsdorff, 2007). Here we will discuss briefly systematic errors: smoothing error, temperature error and errors resulting from the instrumental line shape (ILS). The resulting precision is estimated from the retrieved columns.
Table 1. Smoothing error for two retrievals using different constraints and calculated with different a priori covariances (Sa) addressing (a) the urban variability and (b) the regional variability. The Sa is based on a profile ensemble which is constructed from (a) the MLH retrieval results and the surface concentrations and (b) from MOPITT profile retrievals for winter 2007/2008 in the area $102-90^{\circ} \mathrm{W}$ and $17-21^{\circ} \mathrm{N}$, (the relative information is in respect to the average of the retrieved CO column in Mexico City $=2.8 \times 10^{18}$ molecules $/ \mathrm{cm}^{2}$ ).

\begin{tabular}{lllll}
\hline & & Sa & \multicolumn{2}{c}{ Smoothing error } \\
& & STDEV & Block VMR & Scaling \\
\hline (a) 2 Parameter & in $\left(\right.$ molec $\left./ \mathrm{cm}^{2}\right)$ & $1.07 \mathrm{E} 18$ & $5.9 \mathrm{E} 16$ & $3.2 \mathrm{E} 17$ \\
$\epsilon_{\text {smooth }}^{\mathrm{a}}$ & $\%$ of mean col & 38 & 2.1 & 11 \\
(b) MOPITT & in $\left(\right.$ molec $\left./ \mathrm{cm}^{2}\right)$ & $8.8 \mathrm{E} 16$ & $3.5 \mathrm{E} 16$ & $2.2 \mathrm{E} 16$ \\
$\epsilon_{\text {smooth }}^{\mathrm{b}}$ & $\%$ of mean col & 3.1 & 1.3 & 0.79 \\
Total & in (molec $\left./ \mathrm{cm}^{2}\right)$ & $1.07 \mathrm{E} 18$ & $6.9 \mathrm{E} 16$ & $3.2 \mathrm{E} 17$ \\
& $\%$ of mean col & 38 & 2.5 & 11 \\
\hline
\end{tabular}

\subsection{Smoothing error}

To evaluate how in average the constrained retrieval differs from the true state, the smoothing error $\epsilon_{\text {smooth }}$ is calculated (Rodgers, 1990). (If more than one independent quantities are available, the error is better described by the matrix $\left.\mathbf{S}_{\text {smooth }}\right)$.

$\mathbf{S}_{\text {smooth }}=(\mathbf{A}-\mathbf{1}) \mathbf{S}_{\mathbf{a}}(\mathbf{A}-\mathbf{1})^{t}$

$\epsilon_{\text {smooth }}=\sqrt{\mathbf{S}_{\text {smooth }}}$

The total column averaging kernel (A) is shown in Fig. $5 b$ (red curve for the used retrieval). The covariance matrix $\left(\mathbf{S}_{\mathbf{a}}\right)$, which describes the variability of the $\mathrm{CO}$ profiles, has to be estimated in order to calculate the smoothing error. Two different and statistically independent phenomena can lead to a variation of the $\mathrm{CO}$ profiles motivating two different estimations of the smoothing error: a) Through variations in the $\mathrm{CO}$ emissions, in the mixing layer height and in local dynamics which leads to a strong variability of $\mathrm{CO}$ in Mexico City. b) Through regional transport phenomena and changes of the CO profiles over wider areas due to for example biomass burning. The smoothing error in the column $\epsilon_{\text {smooth }}^{a}$ is calculated for case a) phenomena using a "2-parameter" ensemble of possible $\mathrm{CO}$ profiles constructed with the retrieved mixing layer height and the $\mathrm{CO}$ surface concentrations (the average of the 5 nearest in situ CO measurements). The effect of the variance in the regional background (case b) of $\mathrm{CO}$ on $\epsilon_{\text {smooth }}^{b}$ is estimated using an alternative covariance matrix (see Table 1), constructed from the MOPITT profiles (NCAR MOPITT, 2008). The profile for the ensemble consists of retrieved CO profiles (v.5.93) for the winter of 2007/2008 in the area between $17-21^{\circ} \mathrm{N}$ and $90-105^{\circ} \mathrm{W}$. In Table 1 the resulting smoothing errors from the chosen constraint ("block 
Table 2. Overview of the most important errors in the CO column retrieval.

\begin{tabular}{lllllll}
\hline $\begin{array}{l}\text { Type of errors } \\
\text { Description: }\end{array}$ & $\begin{array}{l}\text { Smoothing } \\
\epsilon_{\text {smooth }}^{1} \epsilon_{\text {smooth }}^{2}\end{array}$ & $\begin{array}{l}\text { Temperature } \\
+5 \mathrm{~K} \text { all layer }\end{array}$ & $\begin{array}{l}\text { ILS } \\
(\text { Sect. 4.3) }\end{array}$ & $\begin{array}{l}\text { Total } \\
\text { systematic }\end{array}$ & measurement & hourly mean \\
\hline in $\left(\mathrm{molec} / \mathrm{cm}^{2}\right)$ & $5.9 \mathrm{E} 16$ & $5.6 \mathrm{E} 15$ & $\sim 2.8 \mathrm{E} 17$ & $2.9 \mathrm{E} 17$ & $1.4 \mathrm{E} 17$ & $3 \mathrm{E} 16$ \\
in $(\%)$ & 2.1 & 0.2 & $\sim 10$ & $\sim 10$ & 4.9 & 1.1 \\
\hline
\end{tabular}

VMR") and for a "profile-scaling" constraint are presented. The chosen $\mathrm{CO}$ retrieval reproduces the $\mathrm{CO}$ amount and its diurnal cycle in the mixing layer quite well (error is less than $5 \%$ ) and the influence of the regional $\mathrm{CO}$ variance seems also to be minimized.

\subsection{Temperature error}

The temperature error, which may be classified as random for a time series based on daily means, can be systematically influenced by solar heating affecting the retrieved diurnal cycle of the CO column. This error was estimated by retrieving the same spectrum with different temperature profiles. The assumed temperature influences the retrieved $\mathrm{CO}$ columns in two ways: a) The absorbance of each molecule changes because the population of the lower state of an absorbing line depends on the temperature and $b$ ) the assumed air densities assumed in the layers vary with temperature. Both parts are separated input parameters in SFIT2 and they have opposite effects on the retrieved columns. For a $5 \mathrm{~K}$ increase in temperature at a solar zenith angle of $42^{\circ}$, the CO column changes by $+2.14 \%$ and by $-1.96 \%$ due to changes in the absorption by molecules and the air density, respectively. The resulting effect on the retrieved $\mathrm{CO}$ column due to this change in temperature is $\sim 0.2 \%$. Finally, both temperature effects cancel each other and the retrieved $\mathrm{CO}$ column is rather independent of the temperature profile for the used spectral window.

\subsection{Error in the ILS}

The instrumental line shape (ILS) plays an important role in FTIR spectroscopy, especially with a moderate spectral resolution of $0.5 \mathrm{~cm}^{-1}$. Previous studies on a similar spectrometer have shown that the ILS results from a rather triangular and slightly asymmetric apodization (Harig et al., 2005, E. Flores-Jardines, personal communication, 2007). Some studies to optimize the retrieval-strategy and evaluate the error related to the ILS have been done. However, the apodization for the solar tracking mode is slightly different since the sun slowly leaves the focus. The effective instrumental line shape and apodization function cannot be derived easily from measurements within the laboratory. A former estimation with a triangular apodization (see ACPD 9-11501, 2009) led too a slightly higher residual and higher $\mathrm{CO}$ columns than the retrieval strategy presented here, which uses a Boxcar apodization and the FOV-parameter of $41.5 \mathrm{mrad}$. This value was found to minimize the residual of the $\mathrm{CO}$ fit tested on an ensemble of various spectra with different solar zenith angles.

To confirm that the new retrieval has a smaller bias as the old version which led to $25 \%$ higher $\mathrm{CO}$ columns, the additional experiment described in Sect. 4.5 was performed. The estimation of a systematic error of $10 \%$ through the ILS is given by the difference between the injected and the retrieved column amount in the test experiment.

\subsection{Random errors}

Random errors affect the precision of the measurement technique. They are by definition randomly different in each measurement and occur due to spectrum preparation, cloud conditions and the noise. Random errors can be reduced by the factor $1 / \sqrt{N}$ (Poisson statistics) by averaging $N$ spectra or their retrieval results. For solar measurements, each recorded spectrum is analyzed individually because the random noise is rather small due to the low resolution of the instrument (Harig, 2004). In the case of the lunar measurements, which have a smaller signal-to-noise ratios, the spectra are averaged over ten minute intervals.

The random error of a fixed time interval can be used to compare the precision of the measurement technique with respect to others. To estimate the random error for the solar measurements, we evaluate the variability of the retrieved columns over a short time interval. A random error for a single measurement of $5 \%$ was estimated by the averaged difference of consecutive measurements and the random error for an hourly mean $(\approx 33$ spectra) was $1.0 \%$. This number corresponds to the average of all time intervals. In the time interval of an hour, first a fitted straight line is subtracted and the standard error is then calculated.

\subsection{Experimental evaluation of the retrieved $\mathrm{CO}$ column}

The precision is estimated from a series of measurements as in the previous section. This does not give insight into sources of errors, but it gives a reliable information about the total statistical error. The calculated total systematic errors in the CO column consists of different particular addressed errors. All these errors are based on estimated variabilities and uncertainties. However, the error analysis from this 

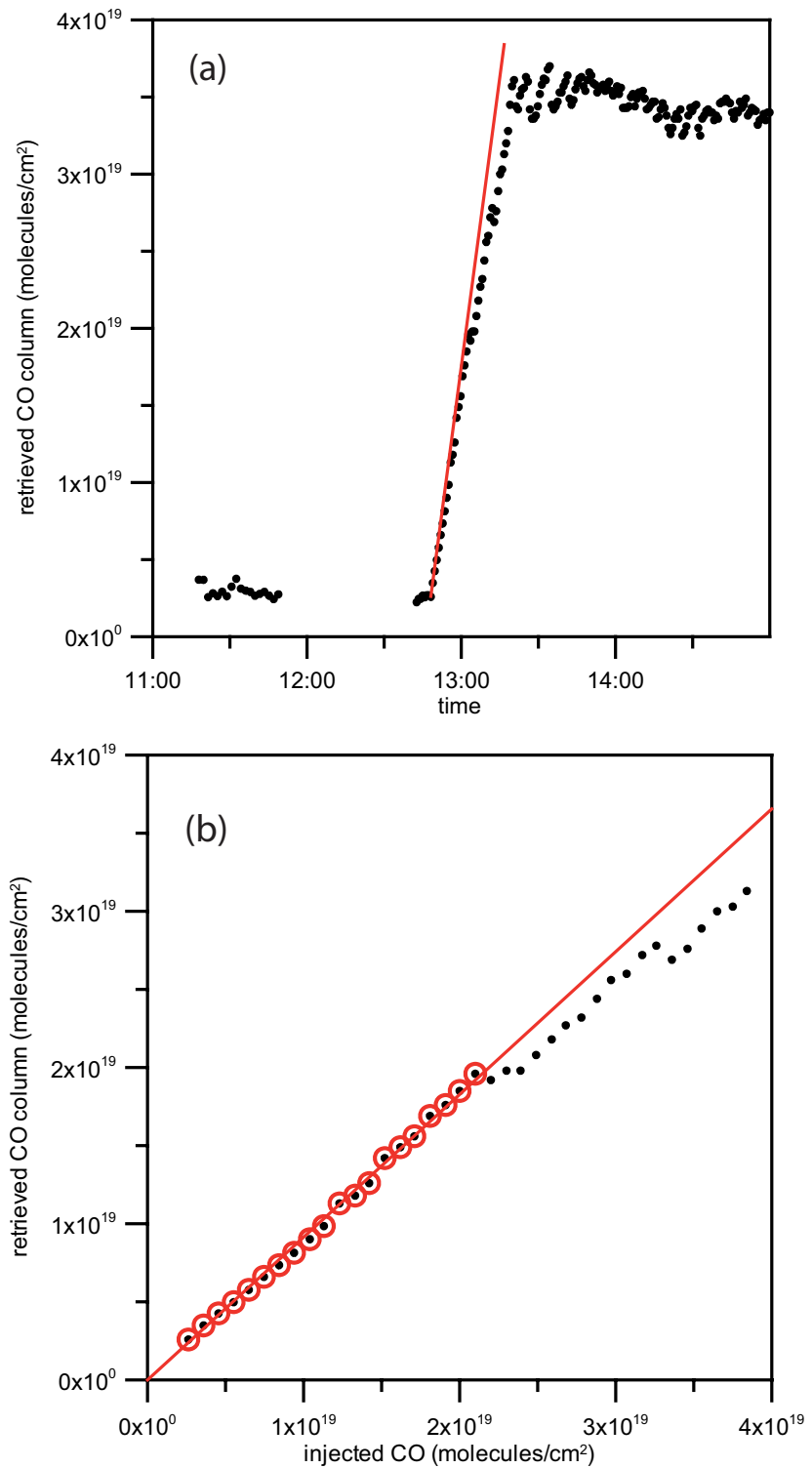

Fig. 6. Evaluation experiment realized on 24 Ferbruary 2009 at the UNAM designed to test the measurement and retrieval performance. (a) The retrieved $\mathrm{CO}$ column is plotted against time as pure $\mathrm{CO}$ was injected into the closed telescope in constant time intervals. (b): A correlation plot between the measured and injected $\mathrm{CO}(5 \mathrm{ml}$ per injection).

bottom-up approach is not always complete or correct. The difference between two different ILS showed that this parameter can lead to a $25 \%$ error.

To check if the $\mathrm{CO}$ column retrieval from solar spectra is overall a good result and to ensure that no important error sources are missing, an additional experiment was done. The cylindrical housing of the telescope was closed by a film that is transparent in the infrared and for a time period when the solar zenith angle did not change significantly, a large amount of $\mathrm{CO}$ was injected into the closed cell. The injection with approximately equal amounts of $\mathrm{CO}$ was repeated every minute during the sun-tracking phases. Figure 6a shows, as expected, a linear increase in the retrieved $\mathrm{CO}$ column and the correlation shows that the retrieval is performing well.

A study with the ILS showed that if there is a systematic difference between assumed and true ILS; the relation between retrieved and true column is not certainly linear for a wide range. This control experiment proves the linear response of the $\mathrm{CO}$ retrieval, shows no significant biases and thus validates the current retrieval set-up.

The slope of the correlation plot in Fig. 6b should be equivalent to the lowest layer averaging-kernel element. Normally, the averaging kernel $\mathbf{A}=\partial \operatorname{col}_{\text {ret }}^{\mathrm{CO}} / \partial \boldsymbol{x}_{\text {true }}^{\mathrm{CO}}$ is calculated using the same forward model as in the retrieval. In the designed experiment, however, the forward simulation is done experimentally and therefore the forward model and the ILS is evaluated. This experiment is limited by a) the estimation in the amount of injected $\mathrm{CO}$ b) the free volume in the telescope housing, c) the mixing time in the telescope and d) the rate of removal of $\mathrm{CO}$ through small holes.

The error in a) is comparably low, as the volume is almost cylindrical and the dead volume (mirrors or other components) is relatively small. The error sources b), c) and d) can lead to an overestimation of the true $\mathrm{CO}$ amount in the telescope. As our comparison shows a retrieved $\mathrm{CO}$ column which is almost $10 \%$ smaller than the estimated $\mathrm{CO}$ amount in the telescope, we consider the value as an upper limit for the bias and assume that the slightly wrong simulation of the ILS leads to the systematic error.

Although this experiment could be used as calibration, in this work the ILS is found independently by optimizing the residual and the test experiment is used to quantify the ILSerror.

\section{Results}

The CO column was measured in Mexico City between October 2007 and February 2008 and the results are presented in this section. The total column can change according to three main, independent mechanisms: 1) A regional variability that can also be detected outside the urban area due to changes in global composition, annual variability or the influence from other sources such as biomass burning. 2) The anthropogenic emission of $\mathrm{CO}$ within the metropolitan area, which should present a diurnal pattern but might vary from day to day. 3) The local and regional meteorological conditions responsible for air flow patterns that affect the pollutant concentrations above the measurement site.

In the first part (Sect. 5.1), measurements that have been taken above the boundary layer are presented. These measurements were performed in order to gain more knowledge about which part of the measured total columns belong to the regional background levels and which can be attributed to the urban air within the mixing layer of Mexico City. In 


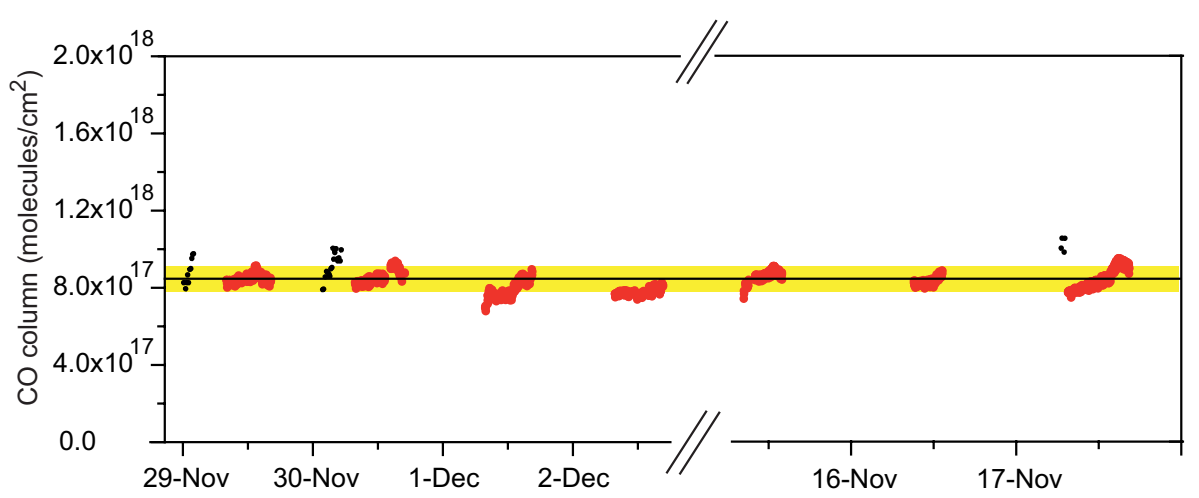

Fig. 7. CO column results at the high-altitude site in Altzomoni $\left(19.12^{\circ} \mathrm{N}, 98.65^{\circ} \mathrm{W}, 4010 \mathrm{~m}\right.$ a.s.1.) located $60 \mathrm{~km}$ south-east of Mexico City during the two measurment campaigns. The CO column is retrieved from solar and lunar infrared spectra from 28 November to 2 December 2007 and 15 to 18 November 2008. The black solid line and the yellow-shaded bar depicts the $8.4 \pm 0.5 \times 10^{17} \mathrm{molecules} / \mathrm{cm}^{2}$ mean value and variability, which are also shown in further figures representing the regional CO background.

Table 3. Results from the retrieved CO column above the mixing layer (Altzomoni remote site) during both campaigns. To avoid the impact of pollution transport detected in the afternoons, only late morning data were used (09:00-13:00 LT).

\begin{tabular}{lllll}
\hline $\begin{array}{c}\text { Altzomoni } \\
\left(10^{18} \text { molecules/cm }{ }^{2}\right)\end{array}$ & $\begin{array}{c}\text { Column } \\
2007\end{array}$ & & $\begin{array}{l}\text { mean sun } \\
(09: 00-13: 00 \mathrm{LT})\end{array}$ & Moon \\
& Minimum & 0.71 & 0.71 & 0.79 \\
& Mean & 0.81 & 0.83 & 0.90 \\
& STDEV & 0.044 & 0.047 & 0.064 \\
& number & 814 & 371 & 27 \\
\hline 2008 & Minimum & 0.72 & 0.72 & \\
& Mean & 0.84 & 0.85 & 0.98 \\
& STDEV & 0.046 & 0.044 & 0.067 \\
& number & 1310 & 878 & 27 \\
\hline $07 / 08$ & & & & \\
& Mean & 0.83 & 0.84 & 1.01 \\
& STDEV & $( \pm 0.05)$ & $( \pm 0.05)$ & 54 \\
\hline & number & 2124 & 1249 & $507)$ \\
\hline
\end{tabular}

Sect. 5.2, the daily means of 62 days during the measurement period are shown in order to identify patterns and possible differences between working days and weekends. Additional coincident information of the measured surface concentration of CO is used in Sect. 5.4 to study the diurnal patterns of column and ground-level $\mathrm{CO}$ and to reconstruct an effective mixing layer height, which is then compared with model results.

\subsection{Total CO column measurements above the boundary layer}

Solar and lunar absorption spectra have been recorded at the high-altitude remote site of Altzomoni, located $60 \mathrm{~km}$ south east of Mexico City and at $4010 \mathrm{~m}$ a.s.l. From these spectra, the total CO column is obtained with a similar retrieval strategy as for spectra taken in Mexico City. Only the constraint was adapted to the assumption that Altzomoni is above the mixing layer and an enhancement in the free troposphere is well represented by a scaling of the a priori profile. A test shows that if in contrary to the presented profile-scalingretrieval only the lowest two layers $(1 \mathrm{~km})$ are allowed to freely adapt, the resulting columns are systematically 5\% lower.

The results of the measurements done between 29 November and 2 December 2007 and 15-19 November 2008 are presented in Fig. 7. There were blue sky conditions during the mornings with some clouds in the afternoons. At night the sky was typically clear, although the moon measurements were sensitive to thin clouds and the available radiation was limited. It can be observed that the $\mathrm{CO}$ column increases slightly in the midday and early afternoon. This suggests that the mixing layer rises above $2 \mathrm{~km}$ and that the urban pollution reaches the Altzomoni site. This is in agreement with a recent study that presents the properties of gases and aerosols at this same research site (Baumgardner et al., 2009). In that study, the anthropogenic influence detected particularly during the afternoons originated from all surrounding regions and not only when the wind came from the Mexico City area.

From the results presented in Fig. 7 and previous studies at this research site, one can assume that the Altzomoni site is usually above the convective mixing layer before noon. In Table 3, the results from the average total columns obtained both from lunar and solar measurements (between 09:00-13:00 LT), are presented. The mean value of $(8.4 \pm 0.45) \times 10^{17}$ molecules $/ \mathrm{cm}^{2}$ is in the expected range for this latitude and altitude which is based on other high altitude CO measurements from NDACC stations in the Northern Hemisphere as for example (Izana $28^{\circ} \mathrm{N}, 2360 \mathrm{~m}$ a.s.l., Jungfraujoch $47^{\circ} \mathrm{N}, \quad 3580 \mathrm{~m}$ a.s.l., Zugspitze $47^{\circ} \mathrm{N}$, 


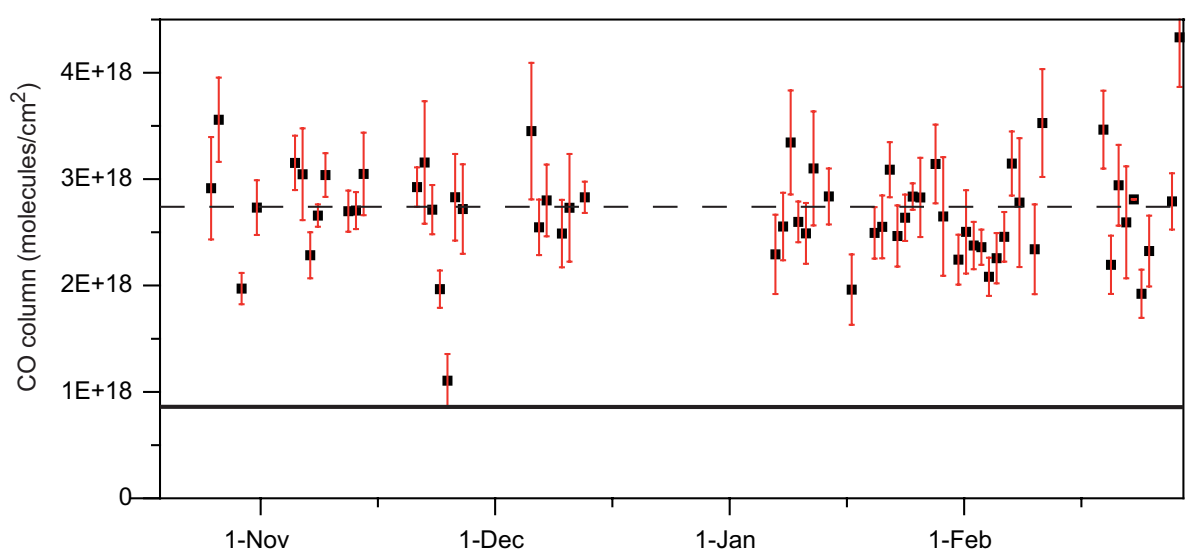

Fig. 8. Time series (15 October 2007 to 29 February 2008) of daily CO columns at the UNAM site taken as late morning (09:00-13:00 LT) averages. The red bars show the STDEV of the averaged data.

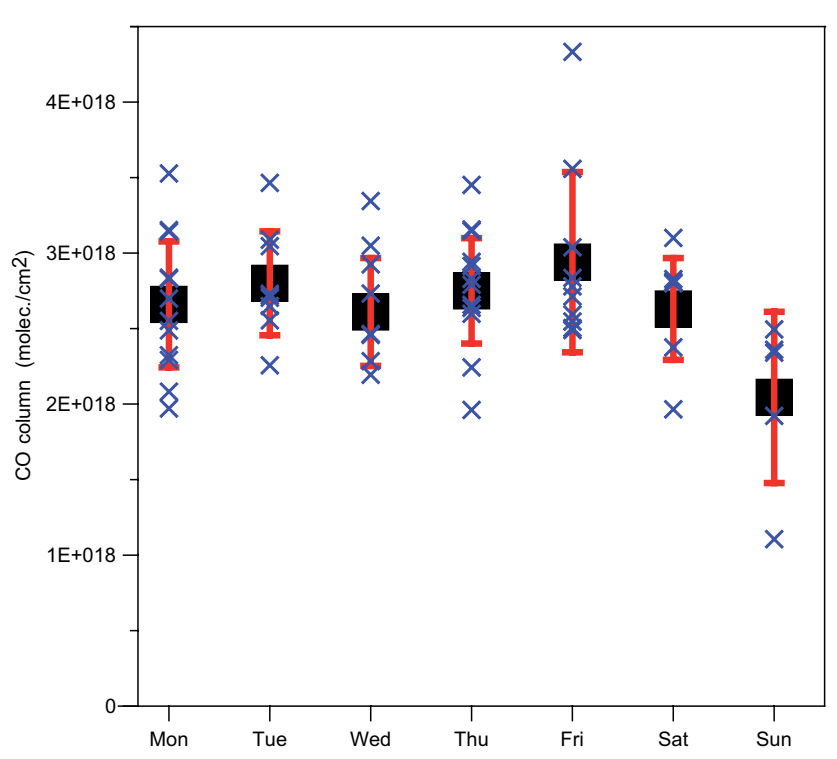

Fig. 9. Blue crosses: Same data as shown in Fig. 8 but sorted by day of the week. Mean column of a specific weekday (black squares) and the corresponding STDEV (red bars).

$2964 \mathrm{~m}$ a.s.1.) for this time of the year (Gardiner et al., 2007; Kramer, 2006). A background lower limit of the $\mathrm{CO}$ column $\left(\operatorname{col}_{\text {altz }}^{\mathrm{co}}\right)=8.4 \times 10^{17}$ molecules $/ \mathrm{cm}^{2}$, corresponding to clear air in the region above $4 \mathrm{~km}$ altitude is used as reference for future analysis and is expected to have a variability smaller than $20 \%$.

\subsection{Day to day variations of the CO columns within Mexico City}

The daily CO columns measured at the UNAM site in Mexico City from October 2007 to February 2008 are presented in Fig. 8. The data, expressed as daily mean values recorded during the 09:00-13:00 LT
Table 4. Results from the retrieved CO column above Mexico City: individual measurements and daily late morning means (9:0013:00 LT).

\begin{tabular}{lllllll}
\hline Mexico & $\begin{array}{c}\text { Sun } \\
\left(10^{18}\right.\end{array}$ & $\begin{array}{c}\text { Moon } \\
\left.\text { molecules } / \mathrm{cm}^{2}\right)\end{array}$ & $\begin{array}{c}\text { all } \\
\text { daily mean }\end{array}$ & \multicolumn{2}{c}{$\begin{array}{c}\text { Sunday } \\
\text { d09:00-13:00 })\end{array}$} \\
\hline Mean & 2.86 & 2.08 & 2.82 & 2.75 & 2.04 & 2.63 \\
STDEV & 0.82 & 0.35 & 0.82 & 0.41 & 0.57 & 0.41 \\
number & 12179 & 651 & 12830 & 57 & 5 & 62 \\
\hline
\end{tabular}

time periods, comprise 57 working days including Saturdays. The mean column measured during the period was $(2.75 \pm 0.4) \times 10^{18}$ molecules $/ \mathrm{cm}^{2}$. The standard deviation (STDEV) within a working day was on average about $5 \%$. We include Saturdays in the working days, as in recent time the traffic conditions and the estimated CO emissions on Saturday are similar to normal working days (Official Inventory, 2008). If the data collected on Saturdays are excluded from the data set, the average $\mathrm{CO}$ total column differs by only $0.4 \%$.

It is evident from the data that, on days with efficient ventilation (emissions are assumed to persist), the total column approximates the background value of $8.4 \times 10^{17}$ molecules $/ \mathrm{cm}^{2}$. The total CO column amount above Mexico City is thus strongly dependent on the wind condition, as can be seen from the large day-to-day variability in Fig. 8. This has also been observed in a time series recorded in Moscow (Fokeeva et al., 2008).

Data was also collected on 5 Sundays during the measurement period. The average total column was found to be $(2.04 \pm 0.57) \times 10^{18}$ molecules $/ \mathrm{cm}^{2}$, which is $26 \%$ lower than the average of the working days. In Fig. 9 the data is presented according to the day of the week. Here the effect that reduced emissions have on the total columns is clearly seen. 
The values measured are consistent with $\mathrm{CO}$ total column values reported previously in the region. During 2003, total columns of $(2-5) \times 10^{18}$ molecules $/ \mathrm{cm}^{2}$ were measured near downtown Mexico City (de Foy et al., 2007) and during the MILAGRO field campaign in 2006, a mean value of $\left(1.74 \times 10^{18}\right.$ molecules $\left./ \mathrm{cm}^{2}\right)$ was measured at the $\mathrm{T} 1$ research site (Tecamac), located $50 \mathrm{~km}$ north east outside of Mexico City (J. Hannigan, personal communication, 2008). The $\mathrm{CO}$ column daily means recorded in Mexico City are similar to the typical CO column above Moscow (156 m a.s.1.). A mean column of $\approx 3.5 \times 10^{18}$ molecules $/ \mathrm{cm}^{2}$ (Fokeeva et al., 2007) in that study resembles the values of Mexico City but is slightly higher, which could be expected from the higher surface pressure affecting the background column.

\subsection{Diurnal and nocturnal behaviour of the $\mathrm{CO}$ column}

As the measurements are taken in a megacity, a strong local source of $\mathrm{CO}$, the columns change according to emissions and horizontal transport. The sinks and sources due to chemical processes are comparably small and can be neglected, so that $\mathrm{CO}$ can be treated as an inert tracer. Both the emissions and horizontal transport have a strong diurnal variability. The emission itself would lead to a monotonous growth of the column while in average the horizontal transport through ventilation keeps a balance, so that both parts are important in the actual CO column above the city. Since the column amount of fresh $\mathrm{CO}$ is extended over the mixing layer, the surface wind speed together with a surface $\mathrm{CO}$ gradient do not provide sufficient information to calculate the loss through transportation. A longer time series and additional meteorological data are needed to portion the $\mathrm{CO}$ column growth rate in the fresh emission and the transportation.

However, the distribution of the wind speed and its correlation with the total column of $\mathrm{CO}$ shows that there are different phases during a day when the horizontal ventilation plays a major or minor role. The hourly mean wind speed values, taken from the PEMBU network (http://pembu.unam.mx/), were linearly interpolated to reach coincidence to the time when the CO column measurement was taken. The average wind speeds in the mornings between 09:00-13:00 L.T. is small (average for all measurements $0.4 \mathrm{~m} / \mathrm{s} \pm 0.3 \mathrm{~m} / \mathrm{s}$ ) and no significant correlation $\left(R^{2}=0.02\right)$ with the $\mathrm{CO}$ column was observed. During this time, vertical transport and fresh emissions dominate vertical distribution and growth of the CO column. In the early afternoon (13:00-16:00 LT) and even stronger in the late afternoon until the evening (16:0022:00 LT), the CO column shows a clear dependence on the ventilation. The correlation coefficient $R^{2}$ between the COcolumn and surface wind speed reaches a value of 0.4 which is rather high considering that the wind speed is measured at the surface and the column dilution depends also on the horizontal gradient of $\mathrm{CO}$ and the actual mixing layer height (MLH).
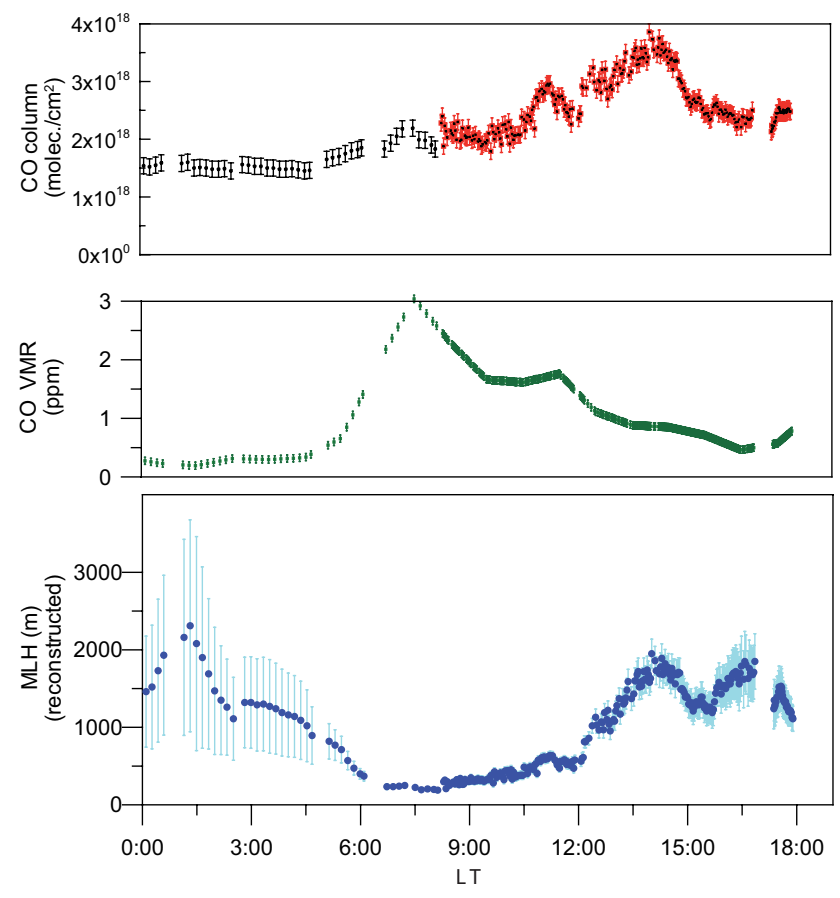

Fig. 10. Top: Example day (25 February 2008) showing the CO column at the UNAM site retrieved from lunar (black) and solar (red) IR spectra. Green: CO VMR at the surface taken as the mean of 5 nearest RAMA stations. Bottom: The reconstructed effective mixing layer height (blue) is presented with error bars calculated as described in Sect. 5.4.2.

This typical behaviour of a decreasing CO column during the early night - early morning can be observed in Figs. 11 and 12 for different days documenting at which time the night jet cleans up the air pollution in the MCMA. This information is relevant for simulating the air quality since if a chemistry transport model was to underestimate the effect of a cleaning night jet, it would overestimate the $\mathrm{CO}$ surface concentration like it is shown in the recent work of Tie et al. (2009). In this case, it would also overestimate the total column amount of $\mathrm{CO}$, however, if the $\mathrm{CO}$ column would be reproduced correctly by the model it would be an indication that only the vertical distribution of $\mathrm{CO}$ is wrong and the vertical transport of the model has a bias. This would be reflected by a wrong mixing layer height, as it is suggested by Tie et al. (2009).

During the morning between 09:00 and 13:00 LT the CO transport is dominated by the vertical transportation and development of the MLH. Here the wind speed has an rather small average of $(0.4 \pm 0.3) \mathrm{m} / \mathrm{s}$. The high STDEV of the wind speed and the low correlation coefficient $R^{2}=0.02$ indicate that it is not possible to directly obtain dilution factors. In this time the $\mathrm{CO}$ column growth-rate differs only slightly from the CO surface emission so that the average of the growth-rates after a classification by the wind patterns, days of the week and filtering with other meteorological parameter 


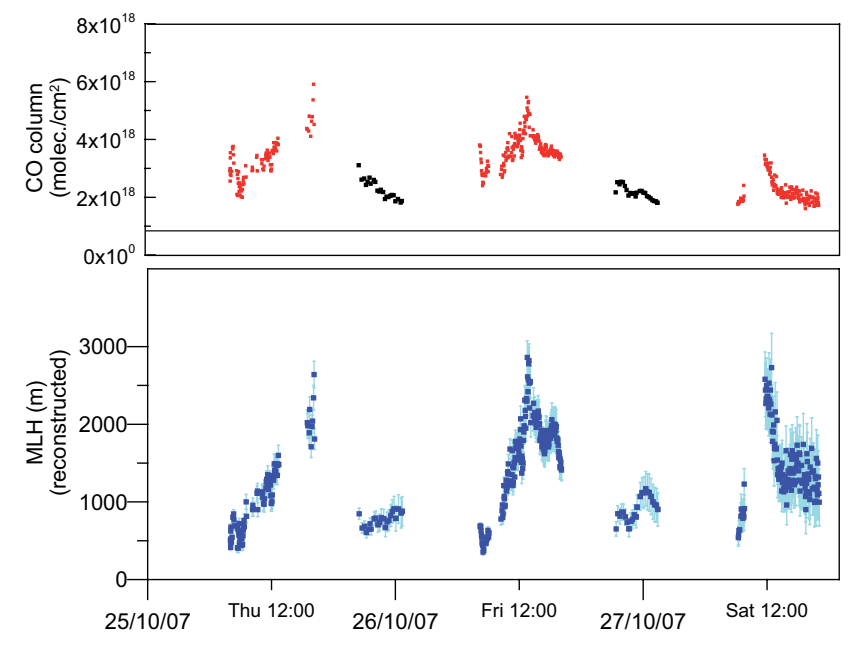

Fig. 11. CO column at the UNAM site during October 2007 retrieved from solar spectra in red and from lunar spectra in black. The solid line represents the background CO column (Fig. 7). The estimated effective MLH (blue) is reconstructed from a model which assumes a single layer.

might allow for a top-down estimation of the emission. As there exist various wind patterns and the emission estimation has to be done individually for each day of the week, the data base of 62 days is too small to investigate emission trends and is the aim of ongoing work.

\subsection{MLH estimation}

Especially for Mexico City, the convective mixing layer height and its dynamics plays a key role in air quality. The in situ measurements of the CO surface concentrations show a completely different diurnal behaviour than the CO column, as shown in the example presented in Fig. 10. Even though surface concentrations and column measurements are dependent on wind conditions and changes in emissions, both are different quantities and a direct comparison is not possible without knowledge of the vertical structure of the atmosphere. In the mornings, a convective mixing layer is formed and $\mathrm{CO}$ accumulates near the surface when the highest in situ concentration is measured. The MLH, driven by solar heating (Whiteman et al., 2000), grows and the CO concentration decreases at the surface, regardless if the total CO column stays constant or increases on a typical day.

\subsubsection{MLH reconstruction}

If the convective mixing layer is well defined, the vertical CO-profile consists of two parts. The "normal" clean air $\mathrm{CO}$ profile above the mixing layer and a part with a nearly constant volume mixing ratio of $\mathrm{CO}\left(\mathrm{VMR}_{\mathrm{co}}\right)$ between surface and upper boundary of the mixing layer $Z_{\mathrm{MLH}}$. The assumption of a homogeneous mixing within the layer is the simplest approximation, but is also motivated by the short

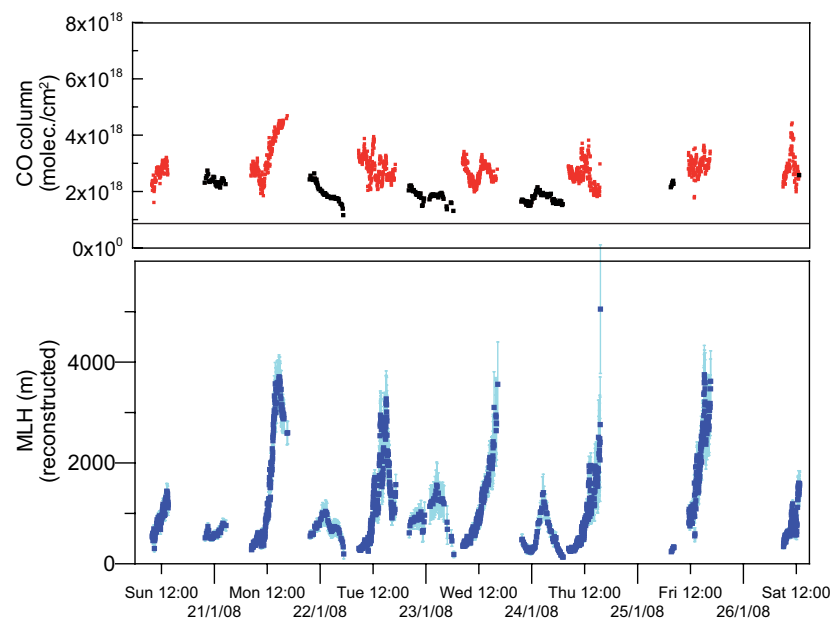

Fig. 12. Same as Fig. 11, but for January 2008.

mixing time and the relatively long lifetime of CO. Even if the mixing layer is not homogeneous, the retrieved effective $\mathrm{Z}_{\mathrm{MLH}}$ is a useful quantity to derive from the atmospheric $\mathrm{CO}$ column. Similarly, the tropospheric and stratospheric columns of nitrous oxide $\left(\mathrm{N}_{2} \mathrm{O}\right)$, methane $\left(\mathrm{CH}_{4}\right)$ and hydrogen fluoride (HF) have been separated by retrieving an effective tropopause height from ground-based solar absorption spectra (Stremme, 2007) and the tropospheric nitrogen dioxide $\left(\mathrm{NO}_{2}\right)$ column can be derived (Sussmann et al., 2005) from a combination of space-borne and ground-based column retrievals.

The total CO column ( $\left.\mathrm{col}_{\mathrm{co}}^{\mathrm{mex}}\right)$ can be written as the sum of two parts as expressed in Eq. (3),

$\operatorname{col}_{\mathrm{co}}^{\mathrm{mex}}=\int_{\mathrm{MLH}_{0}}^{\mathrm{Z}} \mathrm{VMR}_{\mathrm{co}} \cdot \rho_{\mathrm{air}}(z) d z+\operatorname{col}_{\mathrm{co}}^{\mathrm{altz}}$,

where $\mathrm{Z}_{\mathrm{MLH}}$ is the location of the MLH above surface, $\mathrm{VMR}_{\mathrm{co}}$ is the volume mixing ratio of $\mathrm{CO}, \rho_{\text {air }}(z)$ represents the air density for the altitude $z$ and $\mathrm{col}_{\mathrm{co}}^{\text {altz }}$ is the background column of CO. The part above the MLH is estimated from the lower limit value measured at Altzomoni, $\mathrm{col}_{\mathrm{co}}^{\mathrm{altz}} \approx 0.84 \times 10^{17}$ molecules $/ \mathrm{cm}^{2}$, and the air density profile is provided by the daily radiosonde measurements. For determining a representative surface concentration around the UNAM site, the average of the surface CO VMR (hourly mean) of the 5 nearest monitoring stations (PLA, PED, TAX, SUR, UIZ, see Fig. 1) was calculated and to obtain a coincident $\mathrm{VMR}_{\mathrm{co}}$ value, the $\mathrm{CO}$ surface volume mixing ratios are linearly interpolated to the times of the column measurements. The inversion of Eq. (3) to get $\mathrm{Z}_{\mathrm{MLH}}$ is done by an IDL program for each column measurement.

Because $\mathrm{CO}$ is used in this case as a tracer for the MLH (similar to Halland et al., 2008), the reconstruction works better during times of high pollution. The resulting time series for $\mathrm{Z}_{\mathrm{MLH}}$ are shown in Figs. 10-13. The retrieved MLH is independent of the $\mathrm{CO}$ concentration and the $\mathrm{CO}$ surface 
Wind dependent dilution of the CO column.

\begin{tabular}{ccccccc}
\hline Time & \multicolumn{2}{c}{ Wind speed } & Number & Correl. & \multicolumn{2}{c}{ Wind dependence } \\
LT & Mean & STDEV & & $R^{2}$ & Offset & Slope \\
\hline $\mathrm{h}$ & $\mathrm{m} / \mathrm{s}$ & $\mathrm{m} / \mathrm{s}$ & & & $\mathrm{cm}^{-2}$ & $\mathrm{~cm}^{-2} /(\mathrm{m} / \mathrm{s})$ \\
09:00-13:00 & 0.42 & 0.32 & 5148 & 0.02 & $2.9 \mathrm{E} 18$ & $-3.3 \mathrm{E} 17$ \\
13:00-16:00 & 0.96 & 0.65 & 3550 & 0.29 & $3.6 \mathrm{E} 18$ & $-6.9 \mathrm{E} 17$ \\
16:00-22:00 & 0.97 & 0.88 & 1433 & 0.40 & $3.4 \mathrm{E} 18$ & $-6.7 \mathrm{E} 17$ \\
22:00-09:00 & 0.02 & 0.07 & 908 & 0.00 & $2.2 \mathrm{E} 18$ & $2.1 \mathrm{E} 17$ \\
\hline
\end{tabular}
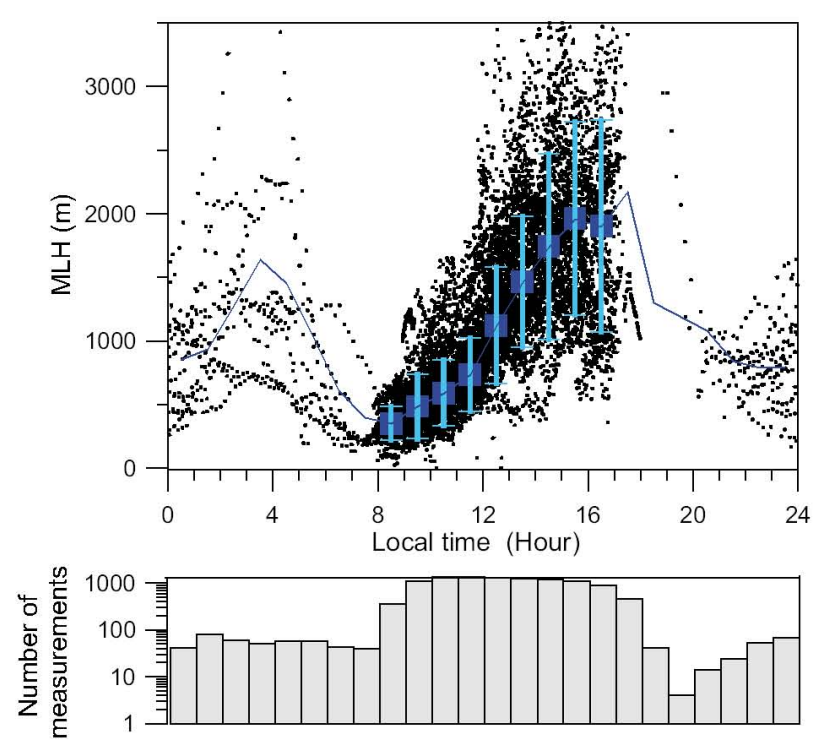

Fig. 13. All MLH values (black dots) reconstructed from the CO measurements as a function of time of the day (15 October 2007 to 29 February 2008 at the UNAM site). The blue squares and bars correspond to the averages and STDEV for the hours with more than 100 measurements. The blue line follows the hourly averages including those times with 10 measurements or more, as gathered from the statistical chart in the bottom.

emissions (even if it is based only on $\mathrm{CO}$ measurements) and should therefore not show a weekly pattern. The reconstructed MLH and its typical diurnal cycle shown in Fig. 13 is consistent with results of other instruments characterizing the vertical structure of the boundary layer (Shaw et al., 2007) and model-based studies (Fast and Zhong, 1998; Whiteman et al., 2000).

The same connection between MLH, column measurements and surface concentration in the Mexico City region has also been observed using $\mathrm{NO}_{2}$ columns (Melamed et al., 2009). But especially in the afternoon and during the night time, the assumption of a well defined single mixing layer might not be valid and further investigation is necessary, Fig. 10. In such cases, the retrieved MLH has to be discussed more carefully since the following scenarios might be possible:
1. The coexistence of two or more different layers in the boundary layer - also reported from measurements on other locations (Wiegner et al., 2006; Emeis et al., 2008) - is not included in the simplified model.

2. A higher CO VMR in the surface-nearest layer than in a less contaminated, aged residual layer could explain a decrease in the estimated $\mathrm{Z}_{\mathrm{MLH}}$ in the afternoon.

3. The air near the surface might be clean at times, but a polluted $\mathrm{CO}$ residual layer may be present above. An inhomogeneity like that would result in an over-estimated height $\mathrm{Z}_{\mathrm{MLH}}$ and could be a typical case during night time, for example on 25 February, Fig. 10.

When applying the MLH retrieval during different seasons of the year, the annual variability of the $\mathrm{CO}$ background in the free troposphere has to be taken into account. This was probably not necessary for the interval of the current study. The annual cycle of the CO column has not yet been studied for Mexico City and surroundings, but it might be somewhat less than the amplitude of $3 E 17$ molecules $/ \mathrm{cm}^{2}$ measured at the Izana station $\left(28^{\circ} \mathrm{N}\right)$ (Kramer, 2006). The relative annual cycle with maxima during the spring and minima during the autumn for this region, can be estimated from the MOPIIT v.3 data (NCAR MOPITT, 2008).

\subsubsection{Error and sensitivity of the retrieved MLH}

Two independent $\mathrm{CO}$ measurements are used to retrieve MLH, which is expected to have similar values like the meteorological quantity, planetary boundary height. For a interpretation of its diurnal cycle and a comparison with model results, Sect. 5.4.3, the sensitivity of the reconstructed MLH to errors in the input parameters (surface and column $\mathrm{CO}$ measurements) is evaluated.

The presented calculation of the MLH uses daily temperature and pressure profiles. Alternatively, an exponentialdecreasing air density could be used to solve Eq. (3) analytically. However, to get an insight in the sensitivity and possible errors in the retrieved MLH, the air density is assumed to be constant in Eq. (3), which leads to an underestimation of around $10 \%$ at $2 \mathrm{~km}$ MLH. The equation can then be solved for MLH in the following manner:

$\mathrm{MLH} \approx \frac{k T}{p} \cdot \frac{\operatorname{col}_{\mathrm{MEX}}-\mathrm{col}_{\mathrm{altz}}}{\mathrm{VMR}}$ 
$\approx\left[5.3 \times 10^{-16} \frac{\mathrm{m} \cdot \mathrm{ppm}}{\mathrm{cm}^{-2}}\right] \frac{\Delta \mathrm{col}}{\mathrm{VMR}}$

The dependence of MLH on the errors due to column measurements results in

$\frac{\partial \mathrm{MLH}}{\partial \Delta \mathrm{col}} \approx\left[5.3 \times 10^{-16} \frac{\mathrm{m} \cdot \mathrm{ppm}}{\mathrm{cm}^{-2}}\right] \frac{1}{\mathrm{VMR}}$

and its dependence on the surface concentration measurements in

$$
\frac{\partial \mathrm{MLH}}{\partial \Delta \mathrm{VMR}} \approx\left[5.3 \times 10^{-16} \frac{\mathrm{m} \cdot \mathrm{ppm}}{\mathrm{cm}^{-2}}\right] \frac{\Delta \mathrm{col}}{\mathrm{VMR}^{2}} .
$$

A typical error of $5 \%$ in the column measurement, motivated through its precision (Sect. 4.4), results in $\delta \mathrm{col}=1.4 \times 10^{17}$ molecuels $/ \mathrm{cm}^{2}$ and for the surface measurements, we get $\delta \mathrm{VMR}=0.0611 \mathrm{ppm}$ if an error of the same magnitude $(5 \%)$ is assumed. These constant errors show that the resulting error in the calculated MLH has a systematic variation which is dependent on the atmospheric state and changes throughout the day.

$\delta_{\mathrm{MLH}}^{\mathrm{tot}}=\sqrt{\left(\frac{\partial \mathrm{MLH}}{\partial \Delta \mathrm{col}} \cdot \delta \mathrm{col}\right)^{2}+\left(\frac{\partial \mathrm{MLH}}{\partial \mathrm{VMR}} \cdot \delta \mathrm{VMR}\right)^{2}}$

The calculated error ( $\delta_{\text {MLH }}^{\text {tot }}$ ) is larger during the night, when the surface concentrations are usually low. Smaller errors result when both column and surface $\mathrm{CO}$ values are larger, as is the case during the morning and early afternoon (see Figs. 10, 11 and 12). The presented error analysis of the MLH-retrieval confirms independently, that the comparison and discussion of the MLH should be restricted to the times between 08:00-16:00 LT, when also the convective layer is well defined, as mentioned in Sect. 5.4.

\subsubsection{Mixing layer height comparison: FTIR vs. model}

In Fig. 13 we present a comparison of the retrieved MLH (Sect. 5.4.1) with that from the North American Regional Reanalysis (NARR) during the measurement period (NCEP, $\left.2008^{1}\right)$. The data from this operational model is available in $3 \mathrm{~h}$ snappshots and has a comparably high resolution since it uses the NCEP Eta model (32 km/45 layer) together with the Regional Data Assimilation System (RDAS), so that there are 3 grid points within the basin and the nearest grid-point of the model is at $19.38^{\circ} \mathrm{N}$ and $99.215^{\circ} \mathrm{W}$, which is centered $10 \mathrm{~km}$ from the measurement site. A direct comparison of the retrieved MLH with data from the daily radiosonde is not very useful because these are launched at 06:00 and 18:00 LT, that is when we have the lowest measurement density. The information of the radiosondes is however assimilated in the NARR model and therefore used indirectly in this comparison.

All model data are interpolated linearly to the time of the measurements. Similar mean values and ranges of the MLH

\footnotetext{
${ }^{1}$ Data available at: http://wwwt.emc.ncep.noaa.gov/mmb/ rreanl/index.html.
}

variability is found, as can be seen in Fig. 14a and a good correlation is obtained in some days, as shown in Fig. 14b. For lower MLHs, the higher values of the model than the reconstructed MLH show the existence of a bias either in the Model or in the FTIR -reconstruction.

For a quantitative comparison, only measurements between 08:00 an 16:00 LT are considered and when the surface wind speed is below $1.2 \mathrm{~m} / \mathrm{s}$. Both selection criteria together with the current retrieval version result in a correlation of $R^{2}=0.58$ (see Fig. 13c). The original correlation when all data was considered (ACPD manuscript, no filtering) was $R^{2}=0.37$. Although the slope in the fit is close to unity, the average MLH from the model is higher and can be described by a systematic offset of $525 \mathrm{~m}$, Eq. 8).

$\mathrm{MLH}_{\text {model }}=0.99 \times \mathrm{MLH}_{\mathrm{FTIR}}-525 \mathrm{~m}$

\subsubsection{Impact of the CO residual layer on the MLH reconstruction}

Theoretically, it could be assumed that a residual layer containing $\mathrm{CO}$ could exist which would produce the bias in the reconstructed MLH. In this case the model in Sect. 5.4.1 and specifically Eq. 3 could be extended by separating the freshly emitted $\mathrm{CO}$ from a older layer of $\mathrm{CO}$ in the boundary layer. To get a better insight, the simplified approximation for the reconstruction of the MLH in Eq. 4 is used for the extension, which results in the following expression, where $\operatorname{col}_{\text {res }}$ and $\mathrm{VMR}_{\text {res }}$ are CO column and VMR of the residual layer:

$\mathrm{MLH} \approx \frac{p}{k T} \cdot \frac{\Delta \mathrm{col}-\mathrm{col}_{\mathrm{res}}}{\mathrm{VMR}-\mathrm{VMR}_{\mathrm{res}}}$

As in the error analysis, we evaluate the dependence of the two unknown quantities $\mathrm{col}_{\text {res }}$ and $\mathrm{VMR}_{\text {res. }}$. If we assume that the NARR model reports the correct MLH, the expression can be used to portion the amount of fresh and old $\mathrm{CO}$ with the assumption that the residual layer of $\mathrm{CO}\left(\mathrm{VMR}_{\mathrm{res}}\right.$, $\mathrm{col}_{\text {res }}$ ) remains constant over the time period.

$\Delta \boldsymbol{m} l \boldsymbol{h}=\frac{p}{k T} \cdot\left(\frac{\mathbf{1}}{\mathbf{v m r}} \frac{\Delta \mathbf{c o l}}{\mathbf{v m r}^{2}}\right)\left(\begin{array}{c}\operatorname{col}_{\mathrm{res}} \\ \mathrm{VMR}_{\mathrm{res}}\end{array}\right)$

Equation 10 is mathematically ill posed and can be solved by a least-square fit. The solution of Eq. 10 gives the value for the surface background concentration $\mathrm{VMR}_{\text {res }}=0.33 \mathrm{ppm}$ and col $_{\text {res }}=-0.15 \times 10^{17}$ molecules $/ \mathrm{cm}^{2}$. Since col res $_{\text {has }}$ to be seen as correction to the measured background value of $\mathrm{col}_{\mathrm{altz}}=8.4 \times 10^{17}$ molecules $/ \mathrm{cm}^{2}$, it can also be negative.

In Fig. 14d, the correlation between the MLH from the model and the reconstructed MLH from this extended model is presented $\left(\mathrm{MLH}_{\text {model }}=0.87 \cdot \mathrm{MLH}_{\mathrm{FTIR}}-35 \mathrm{~m}\right)$. With the assumption of a constant residual layer the coefficient of correlation is improved to $R^{2}=0.63$. If the MLH of the NCEPModel is valid for Mexico City, the result above suggests that generally, the $\mathrm{CO}$ concentration within the boundary layer can be portioned in a fresh $\mathrm{CO}$ with a high variability and a near-constant background level of about $0.33 \mathrm{ppm}$. 

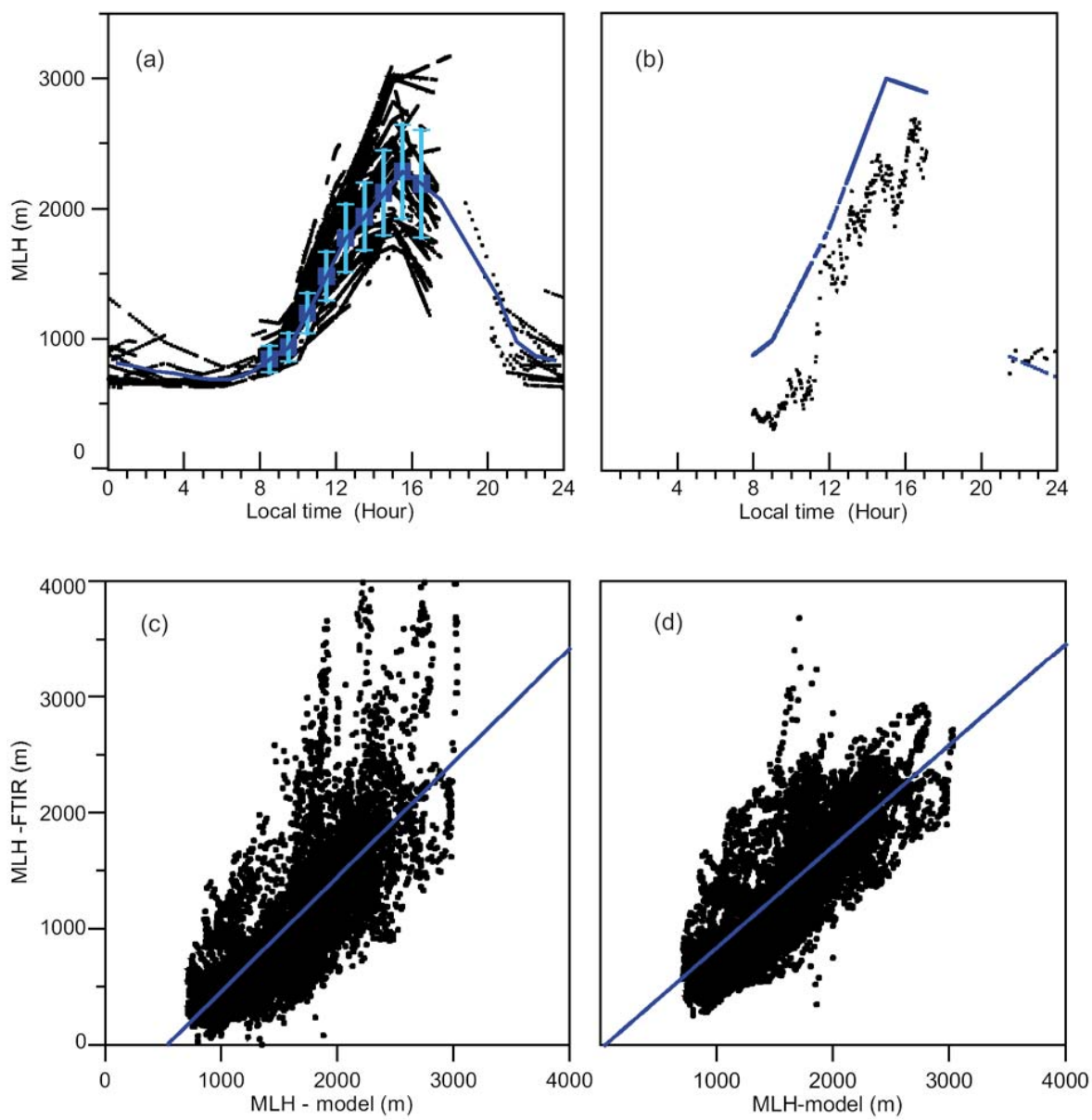

Fig. 14. (a) Same as Fig. 13 but showing model-derived MLH (NCEP, 2008; http://wwwt.emc.ncep.noaa.gov/mmb/rreanl/index.html) as a function of time of the day and interpolated to the measurement times; (b) MLH for a single day comparing the retrieved MLH (black) and model (blue) results. (c) Correlation between retrieved and model MLH (all data between 08:00-16:00 with wind speeds $<1.25 \mathrm{~m} / \mathrm{s}$ and retrieved MLH values $<4000 \mathrm{~m}$. (d) Same as (c) but assuming a CO residual concentration of 0.33 ppm according to the extended model described in Sect. 5.4.4.

\section{Conclusions}

In this work, the column densities of carbon monoxide in Mexico City are reported and their diurnal and daily patterns are presented. The total $\mathrm{CO}$ columns have been retrieved from solar and lunar infrared spectra measured with a low-cost instrumental set-up, which consists of a moderateresolution FTIR spectrometer and a simple scanning device. The quantitative analysis used is described here and the most important error sources are evaluated. The results demonstrate that this experimental set-up can provide reliable information on the absolute column of $\mathrm{CO}$ and most relevant for this study, it can successfully follow its evolution during the day. Also, the CO columns are measured for the first time in a megacity during the night using lunar absorption spectroscopy.

Using an initial data set of 62 days during the winter 2007/2008, a significant difference is seen in the CO column between Sundays $\left(2.04 \pm 0.57 \times 10^{18}\right.$ molecules $\left./ \mathrm{cm}^{2}\right)$ and working days $\left(2.75 \pm 0.41 \times 10^{18}\right.$ molecules $\left./ \mathrm{cm}^{2}\right)$. The clearly observed weekly and diurnal patterns proves that it is possible to gain new information about the anthropogenic emissions from the column measurements. A typical background CO column of $(8.4 \pm 0.5) \times 10^{18}$ molecules $/ \mathrm{cm}^{2}$ was estimated for the period from measurements carried out at the remote, high-altitude research site of Altzomoni (4010 m a.s.l. $60 \mathrm{~km}$ south-east of Mexico City). This background value was used to estimate which part of the column measured in Mexico City is not part of the pollution within the mixing layer.

The high measurement frequency allowed for the investigation of diurnal and nocturnal behaviour. The diurnal change of the CO column and its surface concentration do not correlate but they can complement each other and provide extra information about the vertical dispersion of $\mathrm{CO}$. The mixing layer height $(\mathrm{MLH})$ was reconstructed from the CO column and surface concentration measurements. The diurnal cycle of the reconstructed MLH shows the typical 
boundary layer behaviour (growth between 09:00-13:00 LT), which is a behaviour well known based on model studies and measurements from other instruments. The reconstruction, which is not valid for all times of the day, seems to work well when a single convective layer is present.

The ability to reproduce under special conditions the MLH evolution from only CO measurements, which is in essence independent of the pollution levels and the emission patterns in the city, opens the possibility for a top-down estimation of the $\mathrm{CO}$ emissions to be performed based on ground-based remote sensing measurements. Attempts to pursue this objective will be sought with a larger measurement period and additional observations so that the vertical structure and dynamics of the atmosphere can be better characterized. Also, this work shows the feasibility for using total $\mathrm{CO}$ measurements at this sub-tropical location for the validation of NADIR sounders. This simple experimental approach could be deployed in emerging megacities in other developing countries so that comparisons between the different populated cities, emissions from top-down estimations and for wider satellite validations can be realized.

Acknowledgements. We wish to thank Roland Harig for his support to realize the solar absorption measurements with the scanning infrared system and important discussions. Victor Ramos from the Servicio Meteorologico National is acknowledged for providing the radiosonde data and Ernesto Caetano for the useful discussions and for preparing the model outputs for the MLH. We would like to thank also Jim Hannigan for his support with SFIT2 and for his help in the evaluations, as well for sharing his results from the MILAGRO/INTEXB campaign. Frank Hase is thanked for his support with LINEFITv.11. We also thank Megan Melamed for discussion and both referees for their valuable comments.

Edited by: L. Molina

\section{References}

Barret, B., De Mazière, M., and Mahieu, E.: Ground-based FTIR measurements of $\mathrm{CO}$ from the Jungfraujoch: characterisation and comparison with in situ surface and MOPITT data, Atmos. Chem. Phys., 3, 2217-2223, 2003, http://www.atmos-chem-phys.net/3/2217/2003/.

Baumgardner, D., Grutter, M., Allan, J., Ochoa, C., Rappenglueck, B., Russell, L. M., and Arnott, P.: Physical and chemical properties of the regional mixed layer of Mexico's Megapolis, Atmos. Chem. Phys., 9, 5711-5727, 2009, http://www.atmos-chem-phys.net/9/5711/2009/.

Burton, M. R., Oppenheimer, C., Horrocks, L. A., and Francis, P. W.: Diurnal changes in volcanic plume chemistry observed by lunar and solar occultation spectroscopy, Geophys. Res. Lett., 28, 843-846, doi:10.1029/2000GL008499, 2001.

Clerbaux, C., Edwards, D. P., Deeter, M., Emmons, L., Lamarque, J.-F., Tie, X. X., Massie, S. T., and Gille, J.: Carbon monoxide pollution from cities and urban areas observed by the Terra/MOPITT mission, Geophys. Res. Lett., 35, L03817, doi:10.1029/2007GL032300, 2008. de Foy, B., Lei, W., Zavala, M., Volkamer, R., Samuelsson, J., Mellqvist, J., Galle, B., Martínez, A.-P., Grutter, M., Retama, A., and Molina, L. T.: Modelling constraints on the emission inventory and on vertical dispersion for $\mathrm{CO}$ and $\mathrm{SO}_{2}$ in the Mexico City Metropolitan Area using Solar FTIR and zenith sky UV spectroscopy, Atmos. Chem. Phys., 7, 781-801, 2007, http://www.atmos-chem-phys.net/7/781/2007/.

Dils, B., De Mazière, M., Müller, J. F., Blumenstock, T., Buchwitz, M., de Beek, R., Demoulin, P., Duchatelet, P., Fast, H., Frankenberg, C., Gloudemans, A., Griffith, D., Jones, N., Kerzenmacher, T., Kramer, I., Mahieu, E., Mellqvist, J., Mittermeier, R. L., Notholt, J., Rinsland, C. P., Schrijver, H., Smale, D., Strandberg, A., Straume, A. G., Stremme, W., Strong, K., Sussmann, R., Taylor, J., van den Broek, M., Velazco, V., Wagner, T., Warneke, T., Wiacek, A., and Wood, S.: Comparisons between SCIAMACHY and ground-based FTIR data for total columns of $\mathrm{CO}, \mathrm{CH}_{4}, \mathrm{CO}_{2}$ and $\mathrm{N}_{2} \mathrm{O}$, Atmos. Chem. Phys., 6, 1953-1976, 2006, http://www.atmos-chem-phys.net/6/1953/2006/.

Echle, G., von Clarmann, T., Dudhia, A., Flaud, J.-M., Funke, B., Glatthor, N., Kerridge, B., López-Puertas, M., Martín-Torres, F. J., and Stiller, G. P.: Optimized Spectral Microwindows for Data Analysis of the Michelson Interferometer for Passive Atmospheric Sounding on the Environmental Satellite, Appl. Optics, 39, 5531-5540, 2000.

Emeis, S., Schäfer, K., and Münkel, C.: Long-term observations of the urban mixing-layer height with ceilometers, IOP Conference Series: Earth and Environmental Science, 1, 012027, doi:10.1088/1755-1315/1/1/012027, 2008.

Emmons, L. K., Edwards, D. P., Deeter, M. N., Gille, J. C., Campos, T., Nédélec, P., Novelli, P., and Sachse, G.: Measurements of Pollution In The Troposphere (MOPITT) validation through 2006, Atmos. Chem. Phys., 9, 1795-1803, 2009,

http://www.atmos-chem-phys.net/9/1795/2009/.

Eremenko, M., Dufour, G., Foret, G., Keim, C., Orphal, J., Beekmann, M., Bergametti, G., and Flaud, J.-M.: Tropospheric ozone distributions over Europe during the heat wave in July 2007 observed from infrared nadir spectra recorded by IASI, Geophys. Res. Lett., 35, L18805, doi:10.1029/2008GL034803, 2008.

Fast, J. D. and Zhong, S.: Meteorological factors associated with inhomogeneous ozone concentrations within the Mexico City basin, J. Geophys. Res., 103, 18927-18946, doi:10.1029/98JD01725, 1998.

Finlayson-Pitts, B. J., Ezell, M. J., Jayaweera, T. M., Berko, H. N., and Lai, C. C.: Kinetics of the reactions of $\mathrm{OH}$ with methyl chloroform and methane - Implications for global tropospheric $\mathrm{OH}$ and the methane budget, Geophys. Res. Lett., 19, 1371-1374, doi:10.1029/92GL01279, 1992.

Flores-Jardines, E., Schäfer, K., Harig, R., Rusch, P., and Grutter, $\mathrm{M}$.:Investigation of temperature and gas concentration distributions in hotexhausts (airplanes and burners) by scanning imaging FTIR spectrometry, Proceedings of the SPIE, 5979, 365-376, 2005.

Fokeeva, E. V., Grechko, E. I., Dzhola, A. V., and Rakitin, V. S.: Determination of carbon monoxide pollution of the atmosphere over Moscow with a spectroscopic method, Izv. Atmos. Ocean. Phy.+, 43, 612-617, 2007.

Fokeeva, E. V., Rakitin, V. S., and Kuznetsov, R. D.: Carbon Monoxide Pollution Study of the Atmosphere over Moscow by à Spectroscopic Method, Geophys. Res. Abstr., 10, EGU2008-A- 
10311, 2008.

Forster, P., Ramaswamy, V., Artaxo, P., Berntsen, T., Betts, R., Fahey, D., Haywood, J., Lean, J., Lowe, D., Myhre, G., Nganga, J., Prinn, R., Raga, G., Schulz, M., and Van Dorland, R.: Changes in Atmospheric Constituents and in Radiative Forcing, in: Climate Change 2007: The Physical Science Basis. Contribution of Working Group I to the Fourth Assessment Report of the Intergovernmental Panel on Climate Change, available at: http://www.ipcc.ch/pdf/assessment-report/ar4/wg1/ ar4-wg1-chapter2.pdf, last access: 29 April 2009, 2007.

Gardiner, T., Forbes, A., de Mazière, M., Vigouroux, C., Mahieu, E., Demoulin, P., Velazco, V., Notholt, J., Blumenstock, T., Hase, F., Kramer, I., Sussmann, R., Stremme, W., Mellqvist, J., Strandberg, A., Ellingsen, K., and Gauss, M.: Trend analysis of greenhouse gases over Europe measured by a network of ground-based remote FTIR instruments, Atmos. Chem. Phys., 8, 6719-6727, 2008,

http://www.atmos-chem-phys.net/8/6719/2008/.

Grutter, M., Basaldud, R., Flores, E., and Harig, R.: Optical Remote Sensing for Characterizing the Spatial Distribution of Stack Emissions, Adv. Environ. Monitor., 12, 107-118, 2008a.

Grutter, M., Basaldud, R., Rivera, C., Harig, R., Junkerman, W., Caetano, E., and Delgado-Granados, $\mathrm{H} .: \mathrm{SO}_{2}$ emissions from Popocatépetl volcano: emission rates and plume imaging using optical remote sensing techniques, Atmos. Chem. Phys., 8, 6655-6663, 2008,

http://www.atmos-chem-phys.net/8/6655/2008/.

Halland, J. J., Fuelberg, H. E., Pickering, K. E., and Luo, M.: Identifying convective transport of carbon monoxide by comparing remotely sensed observations from TES with cloud modeling simulations, Atmos. Chem. Phys., 9, 4279-4294, 2009, http://www.atmos-chem-phys.net/9/4279/2009/.

Harig, R.: Passive Remote Sensing of Pollutant Clouds by FourierTransform Infrared Spectrometry: Signal-to-Noise Ratio as a Function of Spectral Resolution, Appl. Optics, 43, 4603-4610, 2004.

Harig, R., Rusch, P., Schäfer, K., and Flores-Jardines, E.: Method for on-site determination of the instrument line shape of mobile remote sensing Fourier transform spectrometers, Proceedings of the SPIE, 5979, 432-441, doi:10.1117/12.627689, 2005.

Harig, R., Matz, G., Rusch, P., Gerhard, H.-H., Gerhard, J.H., and Schlabs, V.: Infrared remote sensing of hazardous vapours: surveillance of public areas during the FIFA Football World Cup 2006, Proceedings of the SPIE, 6538, 65381Z pp., doi:10.1117/12.720227, 2007.

Hase, F., Demoulin, P., Sauval, A. J., Toon, G. C., Bernath, P. F., Goldman, A., Hannigan, J. W., and Rinsland, C. P.: An empirical line-by-line model for the infrared solar transmittance spectrum from 700 to $5000 \mathrm{~cm}^{-1}$, J. Quant. Spectrosc. Ra., 102, 450-463, 2006.

Kramer, I.: Zeitreihen troposphärischer Spurengase abgeleitet aus bodengebundenen FTIR-Messungen, Ph.D. thesis, Universität Karlsruhe, available at: http://digbib.ubka.uni-karlsruhe.de/ volltexte/1000006009, last access: 29 April 2009, 2006.

Luo, M., Rinsland, C., Fisher, B., Sachse, G., Diskin, G., Logan, J., Worden, H., Kulawik, S., Osterman, G., Eldering, A., Herman, R., and Shephard, M.: TES carbon monoxide validation with DACOM aircraft measurements during INTEX-B 2006, J. Geophys. Res., 112, D24S48, doi:10.1029/2007JD008803,
2007.

Melamed, M. L., Basaldud, R., Steinbrecher, R., Emeis, S., RuìzSuárez, L. G., and Grutter, M.: Detection of pollution transport events southeast of Mexico City using ground-based visible spectroscopy measurements of nitrogen dioxide, Atmos. Chem. Phys., 9, 4827-4840, 2009,

http://www.atmos-chem-phys.net/9/4827/2009/.

Molina, L. T. and Molina, M. J.: Air Quality in the Mexico Megacity: An Integrated Assessment, Kluwer Academic Publishers, Dordrecht, The Netherlands, 2002.

NCAR MOPITT: CO profiles downloaded, available at: http://web. eos.ucar.edu/mopitt/, last access: 21 October 2009, 2008.

Notholt, J., Neuber, R., Schrems, O., and Clarmann, T. V.: Stratospheric trace gas concentrations in the Arctic polar night derived by FTIR-spectroscopy with the moon as IR light source, Geophys. Res. Lett., 20, 2059-2062, 1993.

Official Inventory for 2000, Gobierno del Distrito Federal, available at: http://www.sma.df.gob.mx/inventario_emisiones/index. php?op=pub\#, last access: 29 April 2009, 2003.

Official Inventory for 2004, Gobierno del Distrito Federal, available at: http://www.sma.df.gob.mx/inventario_emisiones/index. php?op=pub\#, last access: 29 April 2009, 2004.

Official Inventory for 2006, Gobierno del Distrito Federal, available at: http://www.sma.df.gob.mx/inventario_emisiones/index php?op=pub\#, last access: 29 April 2009, 2008.

Pougatchev, N. S. and Rinsland, C. P.: Spectroscopic study of the seasonal variation of carbon monoxide vertical distribution above Kitt Peak, J. Geophys. Res., 100, 1409-1416, 1995.

Pugacheva, S. G. and Shevchenko, V. V.: The Model of the Moon's Thermal Radiation in the Infrared Spectral Ranges (1012 Microns), 31st Annual Lunar and Planetary Science Conference, abstract no. 1129, 2000.

Rodgers, C. D.: Retrieval of Atmospheric Temperature and Composition From Remote Measurements of Thermal Radiation, Rev. Geophys., 14(4), 609-624, 1976.

Rodgers, C. D.: Characterization and error analysis of profiles retrieved from remote sounding measurements, J. Geophys. Res., 95, 5587-5595, 1990.

Rodgers, C. D.: Invers methods for atmospheric sounding: Theory und Practice, World Scientific Publishing Co. Pte. Ltd, 2000.

Rothman, L. S., Jacquemart, D., Barbe, A., Benner, C. D., Birk, M., Brown, L. R., Carleer, M. R., Chackerian, C., Chance, K., Coudert, L. H., Dana, V., Devi, V. M., Flaud, J.-M., Gamache, R. R., Goldman, A., Hartmann, J.-M., Jucks, K. W., Maki, A. G., Mandin, J.-Y., Massie, S. T., Orphal, J., Perrin, A., Rinsland, C. P., Smith, M. A. H., Tennyson, J., Tolchenov, R. N., Toth, R. A., Vander Auwera, J., Varanasi, P., and Wagner, G.: The HITRAN 2004 molecular spectroscopic database, J. Quant. Spectrosc. Ra., 96, 139-204, 2005.

Schifter, I., Diaz, L., Mugica, V., and Lopez-Salinas, E.: Fuel-based motor vehicle emission inventory for the metropolitan area of Mexico city, Atmos. Environ., 39, 931-940, 2005.

Senten, C., De Mazière, M., Dils, B., Hermans, C., Kruglanski, M., Neefs, E., Scolas, F., Vandaele, A. C., Vanhaelewyn, G., Vigouroux, C., Carleer, M., Coheur, P. F., Fally, S., Barret, B., Baray, J. L., Delmas, R., Leveau, J., Metzger, J. M., Mahieu, E., Boone, C., Walker, K. A., Bernath, P. F., and Strong, K.: Technical Note: New ground-based FTIR measurements at Ile de La Réunion: observations, error analysis, and comparisons with 
independent data, Atmos. Chem. Phys., 8, 3483-3508, 2008, http://www.atmos-chem-phys.net/8/3483/2008/.

SMN (Servicio Meteorologico Nacional): Radiosondes daily at 0 and 12 UTC in Mexico City, available at: http://smn.cna.gob.mx, last access: 29 April 2009, 2008.

Shaw, W. J., Pekour, M. S., Coulter, R. L., Martin, T. J., and Walters, J. T.: The daytime mixing layer observed by radiosonde, profiler, and lidar during MILAGRO, Atmos. Chem. Phys. Discuss., 7, 15025-15065, 2007,

http://www.atmos-chem-phys-discuss.net/7/15025/2007/.

Steck, T.: Methods for determining regularization for atmospheric retrieval problems, Appl. Optics, 41, 1788-1797, 2002.

Stephens, S., Madronich, S., Wu, F., Olson, J. B., Ramos, R., Retama, A., and Muñoz, R.: Weekly patterns of México City's surface concentrations of $\mathrm{CO}, \mathrm{NO}_{\mathrm{x}}, \mathrm{PM}_{10}$ and $\mathrm{O}_{3}$ during 19862007, Atmos. Chem. Phys., 8, 5313-5325, 2008, http://www.atmos-chem-phys.net/8/5313/2008/.

Stremme, W.: Bestimmung hoehenaufgeloester Trends der Spurengase $\mathrm{O}_{3}, \mathrm{~N}_{2} \mathrm{O}$ und $\mathrm{CH}_{4}$ mit Hilfe der solaren Infrarotspektroskopie am Standort Zugspitze, Ph.D. thesis, Universität Augsburg, available at: http://www.opus-bayern.de/uni-augsburg/ volltexte/2007/551/, last access: 29 April 2009, 2007.

Sussmann, R. and Borsdorff, T.: Technical Note: Interference errors in infrared remote sounding of the atmosphere, Atmos. Chem. Phys., 7, 3537-3557, 2007,

http://www.atmos-chem-phys.net/7/3537/2007/.

Sussmann, R. and Buchwitz, M.: Initial validation of ENVISAT/SCIAMACHY columnar CO by FTIR profile retrievals at the Ground-Truthing Station Zugspitze, Atmos. Chem. Phys., 5, 1497-1503, 2005,

http://www.atmos-chem-phys.net/5/1497/2005/.

Sussmann, R., Stremme, W., Burrows, J. P., Richter, A., Seiler, W., and Rettinger, M.: Stratospheric and tropospheric $\mathrm{NO}_{2}$ variability on the diurnal and annual scale: a combined retrieval from ENVISAT/SCIAMACHY and solar FTIR at the Permanent Ground-Truthing Facility Zugspitze/Garmisch, Atmos. Chem. Phys., 5, 2657-2677, 2005,

http://www.atmos-chem-phys.net/5/2657/2005/.

Tie, X., Madronich, S., Li, G., Ying, Z., Zhang, R., Garcia, A., LeeTaylor, J., and Liu, Y.: Characterizations of chemical oxidants in Mexico City: A regional chemical/dynamical model (WRFChem) study, Atmos. Environ., 41, 1989-2008, 2007.

Tie, X., Madronich, S., Li, G., Ying, Z., Weinheimer, A., Apel, E., and Campos, T.: Simulation of Mexico City plumes during the MIRAGE-Mex field campaign using the WRF-Chem model, Atmos. Chem. Phys., 9, 4621-4638, 2009, http://www.atmos-chem-phys.net/9/4621/2009/.

Tikhonov, A.: On the solution of incorrectly stated problems and a method of regularization, Dokl. Akad. Nauk SSSR+, 151, 501504, 1963.
Velazco, V., Notholt, J., Warneke, T., Lawrence, M., Bremer, H., Drummond, J., Schulz, A., Krieg, J., and Schrems, O.: Latitude and altitude variability of carbon monoxide in the Atlantic detected from ship-borne Fourier transform spectrometry, model, and satellite data, J. Geophys. Res., 110, D09306, doi:10.1029/2004JD005351, 2005.

von Clarmann, T. and Grabowski, U.: Elimination of hidden a priori information from remotely sensed profile data, Atmos. Chem. Phys., 7, 397-408, 2007,

http://www.atmos-chem-phys.net/7/397/2007/.

von Clarmann, T., Grabowski, U., and Kiefer, M.: On the role of non-random errors in inverse problems in radiative transfer and other applications, J. Quant. Spectrosc. Ra., 71, 39-46, 2001.

West, J. J., Zavala, M. A., Molina, L. T., Molina, M. J., San Martini, F., McRae, G. J., Sosa-Iglesias, G., and Arriaga-Colina, J. L.: Modeling ozone photochemistry and evaluation of hydrocarbon emissions in the Mexico City metropolitan area, J. Geophys. Res.-Atmos., 109, 19312-19327, doi:10.1029/2004JD004614, 2004.

Whiteman, C. D., Zhong, S., Bian, X., Fast, J. D., and Doran, J. C.: Boundary layer evolution and regional-scale diurnal circulations over the Mexico Basin and Mexican plateau, J. Geophys. Res. 105, 10081-10102, doi:10.1029/2000JD900039, 2000.

Wiegner, M., Emeis, S., Freudenthaler, V., Heese, B., Junkermann, W., Münkel, C., Schäfer, K., Seefeldner, M., and Vogt, S.: Mixing layer height over Munich, Germany: Variability and comparisons of different methodologies, J. Geophys. Res., 111, 2005JD006593, doi:10.1029/2005JD006593, 2006.

Yurganov, L. N., Blumenstock, T., Grechko, E. I., Hase, F., Hyer, E. J., Kasischke, E. S., Koike, M., Kondo, Y., Kramer, I., Leung, F.-Y., Mahieu, E., Mellqvist, J., Notholt, J., Novelli, P. C., Rinsland, C. P., Scheel, H. E., Schulz, A., Strandberg, A., Sussmann, R., Tanimoto, H., Velazco, V., Zander, R., and Zhao, Y.: A quantitative assessment of the 1998 carbon monoxide emission anomaly in the Northern Hemisphere based on total column and surface concentration measurements, J. Geophys. Res., 109, D15305, doi:10.1029/2004JD004559, 2004.

Yurganov, L. N., Duchatelet, P., Dzhola, A. V., Edwards, D. P., Hase, F., Kramer, I., Mahieu, E., Mellqvist, J., Notholt, J., Novelli, P. C., Rockmann, A., Scheel, H. E., Schneider, M., Schulz, A., Strandberg, A., Sussmann, R., Tanimoto, H., Velazco, V., Drummond, J. R., and Gille, J. C.: Increased Northern Hemispheric carbon monoxide burden in the troposphere in 2002 and 2003 detected from the ground and from space, Atmos. Chem. Phys., 5, 563-573, 2005, http://www.atmos-chem-phys.net/5/563/2005/.

Zhang, Y., Dubey, M. K., Olsen, S. C., Zheng, J., and Zhang, R.: Comparisons of WRF/Chem simulations in Mexico City with ground-based RAMA measurements during the 2006MILAGRO, Atmos. Chem. Phys., 9, 3777-3798, 2009, http://www.atmos-chem-phys.net/9/3777/2009/. 